Annales Geophysicae (2001) 19: 1163-1181 C European Geophysical Society 2001

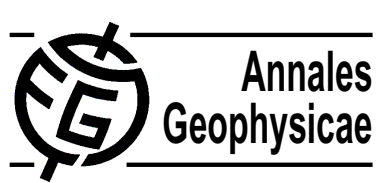

\title{
Stratospheric ozone depletion during the 1995-1996 Arctic winter: 3-D simulations on the potential role of different PSC types
}

\author{
J. Hendricks ${ }^{1, *}$, F. Baier ${ }^{1, \dagger}$, G. Günther ${ }^{2}$, B. C. Krüger ${ }^{3}$, and A. Ebel ${ }^{1}$ \\ ${ }^{1}$ Institut für Geophysik und Meteorologie, Universität zu Köln, EURAD, Aachener Str. 201-209, D-50931 Köln, Germany \\ *now at: DLR, Institut für Physik der Atmosphäre, Oberpfaffenhofen, D-82234 Weßling, Germany \\ ${ }^{\dagger}$ now at: DLR, Deutsches Fernerkundungsdatenzentrum, Oberpfaffenhofen, D-82234 Weßling, Germany \\ ${ }^{2}$ Institut für Stratosphärische Chemie, Forschungszentrum Jülich, D-52425 Jülich, Germany \\ ${ }^{3}$ Institut für Meteorologie und Physik, Universität für Bodenkultur Wien, Türkenschanzstr. 18, A-1180 Wien, Austria
}

Received: 16 November 2000 - Revised: 13 June 2001 - Accepted: 20 June 2001

\begin{abstract}
The sensitivity of modelled ozone depletion in the winter Arctic stratosphere to different assumptions of prevalent PSC types and PSC formation mechanisms is investigated. Three-dimensional simulations of the winter 1995/96 are performed with the COlogne Model of the Middle Atmosphere (COMMA) by applying different PSC microphysical schemes. Model runs are carried out considering either liquid or solid PSC particles or a combined microphysical scheme. These simulations are then compared to a model run which only takes into account binary sulfate aerosols. The results obtained with the three-dimensional model agree with trajectory-box simulations performed in previous studies. The simulations suggest that conditions appropriate for type Ia PSC existence $\left(T<T_{\mathrm{NAT}}\right)$ occur over longer periods and cover larger areas when compared to conditions of potential type Ib PSC existence. Significant differences in chlorine activation and ozone depletion occur between the simulations including only either liquid or solid PSC particles. The largest differences, occurring over large spatial scales and during prolonged time periods, are modelled first, when the stratospheric temperatures stay below $T_{\mathrm{NAT}}$, but above the threshold of effective liquid particle growth and second, in the case of the stratospheric temperatures remaining below this threshold, but not falling below the ice frost point. It can be generally concluded from the present study that differences in PSC microphysical schemes can cause significant fluctuations in ozone depletion modelled for the winter Arctic stratosphere.
\end{abstract}

Key words. Atmospheric composition and structure (aerosols and particles; cloud physics and chemistry; middle atmosphere composition and chemistry)

Correspondence to: J. Hendricks

(Johannes.Hendricks@dlr.de)

\section{Introduction}

It is now well established that the occurrence of polar stratospheric clouds (PSCs) in the winter polar stratosphere and the related heterogeneous chemistry can induce strong chlorine activation and subsequent ozone depletion (e.g. WMO, 1995, 1999). PSC particles can be composed of crystalline nitric acid trihydrate (NAT, Type Ia PSCs) (Hanson and Mauersberger, 1988) or supercooled ternary $\mathrm{H}_{2} \mathrm{SO}_{4} / \mathrm{HNO}_{3} / \mathrm{H}_{2} \mathrm{O}$ solutions (STS, Type Ib PSCs) (e.g. Carslaw et al., 1994; Tabazadeh et al., 1994). Type I PSCs can occur even above the ice frost point $\left(T_{\text {ice }}\right)$. At temperatures below $T_{\text {ice }}$, PSC particles consisting of water-ice (Type II PSCs) can be observed (e.g. Poole and McCormick, 1988). Since temperatures in the Arctic stratosphere fall infrequently below $T_{\text {ice }}$ over prolonged time periods and large spatial scales, type I PSCs are observed much more frequently than type II PSCs during Arctic winters (e.g. Browell et al., 1990; Dye et al., 1992; Biele et al., 1998).

The rates of heterogeneous reactions on type I PSC particles significantly depend on the particles phase (Ravishankara and Hanson, 1996). Hence, the microphysical state of type I PSCs may influence ozone depletion rates. This further implies that stratospheric ozone loss simulated by atmospheric chemistry models may be affected by the respective concepts of PSC schemes applied. Several recent model studies were focussed on quantifying this effect. Sessler et al. (1996) performed simulations of ozone depletion in the Arctic winter stratosphere considering various PSC schemes. A chemistry-box-model was applied in that study assuming typical conditions encountered in the Arctic winter stratosphere at $50 \mathrm{hPa}$. Additionally, a two-dimensional (2-D) chemistry-transport-model (CTM) was employed to simulate ozone depletion on the $465 \mathrm{~K}$ isentropic surface during the winter 1994/95. Upper and lower limits for ozone loss were modeled when type I PSCs are considered to be composed of NAT or STS, respectively. Assuming NAT par- 
Table 1. Chemical constituents and families included in the model

\begin{tabular}{|c|c|}
\hline \multicolumn{2}{|l|}{ Species } \\
\hline Transported & Nontransported \\
\hline $\mathrm{O}_{x}\left(\mathrm{O}\left({ }^{1} \mathrm{D}\right)+\mathrm{O}\left({ }^{3} \mathrm{P}\right)+\mathrm{O}_{3}\right)$ & $\mathrm{O}\left({ }^{1} \mathrm{D}\right)$ \\
\hline $\mathrm{HO}_{x}\left(\mathrm{H}+\mathrm{OH}+\mathrm{HO}_{2}\right)$ & $\mathrm{O}\left({ }^{3} \mathrm{P}\right)$ \\
\hline $\mathrm{H}_{2} \mathrm{O}_{2}$ & $\mathrm{O}_{3}$ \\
\hline $\mathrm{H}_{2} \mathrm{O}$ (gas-, liquid- and solid-phase) & $\mathrm{O}_{2}$ \\
\hline $\mathrm{NO}_{x}\left(\mathrm{NO}+\mathrm{NO}_{2}\right)$ & $\mathrm{H}$ \\
\hline $\mathrm{NO}_{3}$ & $\mathrm{OH}$ \\
\hline $\mathrm{N}_{2} \mathrm{O}$ & $\mathrm{HO}_{2}$ \\
\hline $\mathrm{N}_{2} \mathrm{O}_{5}$ & NO \\
\hline $\mathrm{HNO}_{3}$ (gas-, liquid- and solid-phase) & $\mathrm{NO}_{2}$ \\
\hline $\mathrm{HNO}_{4}$ & $\mathrm{~N}_{2}$ \\
\hline $\mathrm{ClO}_{x}(\mathrm{Cl}+\mathrm{ClO})$ & $\mathrm{Cl}$ \\
\hline $\mathrm{Cl}_{2} \mathrm{O}_{2}$ & $\mathrm{ClO}$ \\
\hline $\mathrm{OClO}$ & $\mathrm{Br}$ \\
\hline $\mathrm{Cl}_{2}$ & $\mathrm{BrO}$ \\
\hline $\mathrm{HCl}$ & $\mathrm{H}_{2}{ }^{a}$ \\
\hline $\mathrm{HOCl}$ & $\mathrm{CH}_{4}{ }^{a}$ \\
\hline $\mathrm{ClONO}_{2}$ & $\mathrm{CH}_{3} \mathrm{Cl}^{a}$ \\
\hline $\mathrm{BrO}_{x}(\mathrm{Br}+\mathrm{BrO})$ & $\mathrm{CCl}_{4}{ }^{a}$ \\
\hline $\mathrm{BrCl}$ & $\mathrm{CFCl}_{3}{ }^{a}$ \\
\hline $\mathrm{HBr}$ & $\mathrm{CF}_{2} \mathrm{Cl}_{2}{ }^{a}$ \\
\hline $\mathrm{HOBr}$ & $\mathrm{CHF}_{2} \mathrm{Cl}^{a}$ \\
\hline $\mathrm{BrONO}_{2}$ & $\mathrm{CF}_{2} \mathrm{ClCFCl}_{2}{ }^{a}$ \\
\hline \multirow[t]{4}{*}{$\mathrm{H}_{2} \mathrm{SO}_{4}$ (liquid- and solid-phase) } & $\mathrm{CH}_{3} \mathrm{CCl}_{3}{ }^{a}$ \\
\hline & $\mathrm{CH}_{3} \mathrm{Br}^{a}$ \\
\hline & $\mathrm{CF}_{2} \mathrm{ClBr}^{a}$ \\
\hline & $\mathrm{CF}_{3} \mathrm{Br}^{a}$ \\
\hline
\end{tabular}

${ }^{a}$ Constant 2-D distribution assumed

ticles, a larger ozone decline is simulated than in the case of STS. Differences in ozone mixing ratio modelled for the late winter range between 0.1 and $0.5 \mathrm{ppmv}$ in the performed simulations. Brühl et al. (1997) used a trajectory-box-model to simulate stratospheric ozone loss over the Arctic during the four winters from 1992/93 to 1995/96. Similar to the work of Sessler et al. (1996), respective simulations considering type I PSCs to be solid or liquid were compared in that study. Differences in the modelled late winter ozone mixing ratio of $0.1-0.2$ ppmv on the 425 to $465 \mathrm{~K}$ isentropic levels were simulated. In contrast to the results of Sessler et al. (1996), during the winter 1994/95 simulation, liquid PSC particles induced the largest ozone loss. The results of Brühl et al. (1997) agree well with trajectory calculations by Carslaw et al. (1997). Potential reasons for the discrepancies in the sign of the PSC scheme effect occurring between the work of Sessler et al. (1996) and the two other studies are differences in uptake coefficients of heterogeneous reactions on NAT and deviations in NAT formation thresholds which may significantly impact modelled ozone depletion (Carslaw et al., 1997). Massie et al. (2000) performed 3-D simulations on the chemistry of the Arctic stratosphere during the winter 1995/96. They focussed on chlorine activation in December 1995 and early January 1996. Employing different microphysical schemes, they modelled significant differences in active chlorine concentrations within the polar vortex. The study suggests that chlorine activation simulated for early winter $1995 / 96$ is larger when NAT particle formation is taken into account compared to simulations where only liquid particles are considered.

The findings of the previous studies indicate that differences in the PSC schemes applied in stratospheric chemistry models can cause significant variations in the ozone concentration simulated for the Arctic winter lower stratosphere. For late winter/early spring, when ozone depletion is the strongest, maximum differences in ozone concentration of around $20 \%$ are simulated. However, since exchange with ambient air masses is not represented in the trajectory and box calculations and vertical diabatic mass exchange is neglected in the 2-D CTM simulations, it remains unclear whether these results are transferable to 3-D model calculations. (In the work of Massie et al. (2000), ozone depletion is not considered). Hence the objective of the present study is to reinvestigate the effect of different concepts of PSC schemes on modelled ozone depletion by means of 3-D calculations. Simulations were performed with the COlogne Model of the Middle Atmosphere (COMMA) employing a NAT, an STS and a more comprehensive PSC scheme which allows the freezing of STS particles. The model calculations were carried out for the Arctic winter 1995/96 which was characterized by very low stratospheric temperatures and a strong ozone decline over the polar region and northern Europe.

The next section provides a model description and an illustration of the different PSC schemes employed. In Sect. 3, the methodology of this study is explained. Furthermore, the results are presented and discussed. The main conclusions are drawn in Sect. 4.

\section{Model description}

\subsection{The dynamical module}

The COMMA dynamical module was developed from the global mechanistic model of the middle atmosphere formulated by Rose (1983). An early version of the module including the lower thermosphere was described by Jakobs et al. (1986). The module solves the primitive dynamical equations on a Eulerian grid for the altitude range from the surface up to a $150 \mathrm{~km}$ altitude. The model atmosphere is driven by explicitly calculated heating and cooling rates due to solar and terrestrial radiation, as described by Dameris et al. (1991) and Berger and Dameris (1993). Time tendencies of horizontal momentum and temperature fields are integrated using a diffusive leap-frog scheme (Haltiner and Williams, 1980). In order to guarantee Courant stability, a zonal Fourier filter is applied to the prognostic variables at high latitudes (Holloway et al., 1973). Model physics includes a first order approximation of gravity wave drag using generalized Rayleigh friction in the functional form described by Schoeberl and Strobel (1978). For a detailed 
description of the COMMA dynamical module, its validation and application, see Dameris et al. (1991), Berger and Dameris (1993), Berger and Ebel (1995), Günther and Dameris (1995) and Berger and von Zahn (1999).

In order to simulate the chemistry and transport of atmospheric constituents in the lower stratosphere and troposphere during real winter episodes, the model-prognostic fields were replaced by interpolated 6 hourly European Centre for Medium Range Weather Forecasts (ECMWF) analyses at all grid levels below $10 \mathrm{hPa}$. This hybrid setup corresponds to an off-line chemistry-transport-model representing the altitude range below $10 \mathrm{hPa}$ coupled with a mechanistic model operating above that pressure level using ECMWF analyses as a lower boundary condition. The advantages of such a hybrid model over a simple CTM with an upper boundary at $10 \mathrm{hPa}$ were shown by Baier (2000). Comparing model ozone to ozone observations provided by the Microwave Limb Sounder (MLS) on board the Upper Atmospheric Research Satellite (UARS) (Froidevaux et al., 1996), Baier (2000) demonstrated that the hybrid model results show a better resemblance with the MLS data compared to the CTM output. This is primarily due to the hybrid model providing a more realistic representation of stratospheric circulation since significant vertical mass fluxes can occur at $10 \mathrm{hPa}$. In the model setup used in this study, the transport of atmospheric constituents is simulated using the flux-corrected advection algorithm described by Bott (1992). The adaption of the algorithm for application in COMMA was described by Günther (1995) and Günther and Dameris (1995) considering fourth-order polynomial interpolation.

For the simulation of the winter 1995/96, a model version was employed which operates on a spherical grid with zonal and meridional resolutions of $5.6^{\circ}$ and $5.0^{\circ}$ degrees, respectively. A vertical logarithmic pressure coordinate $z=$ $H \ln \left(p_{0} / p\right)$ with a constant scale height of $H=7 \mathrm{~km}$ and a surface pressure of $p_{0}=1013 \mathrm{hPa}$ was chosen. With respect to numerical efficiency, the vertical resolution was limited to increments of $\Delta z=5.7 \mathrm{~km}$. Regarding the large vertical extent of the regions showing temperatures below the PSC formation threshold during the winter 1995/96 and the resulting large vertical extent of effective chlorine activation (Santee et al., 1996), the use of a comparatively low vertical grid resolution is justified in this special case.

\subsection{The chemical module}

The chemistry module was developed on the basis of the gas phase photochemical model described by Krüger and Fabian (1986). The module treats chemical transformations of 56 atmospheric constituents (Table 1). Chemical processing is performed for the altitude range from the surface up to $80 \mathrm{~km}$. For the "transported" species (Table 1), the full continuity equation including advection and chemical changes is solved. The "nontransported" species include fast-reactive constituents with chemical life times much smaller than transport timescales. The "nontransported" species also include several long-lived source gases
Table 2. Photolysis reactions included in the model

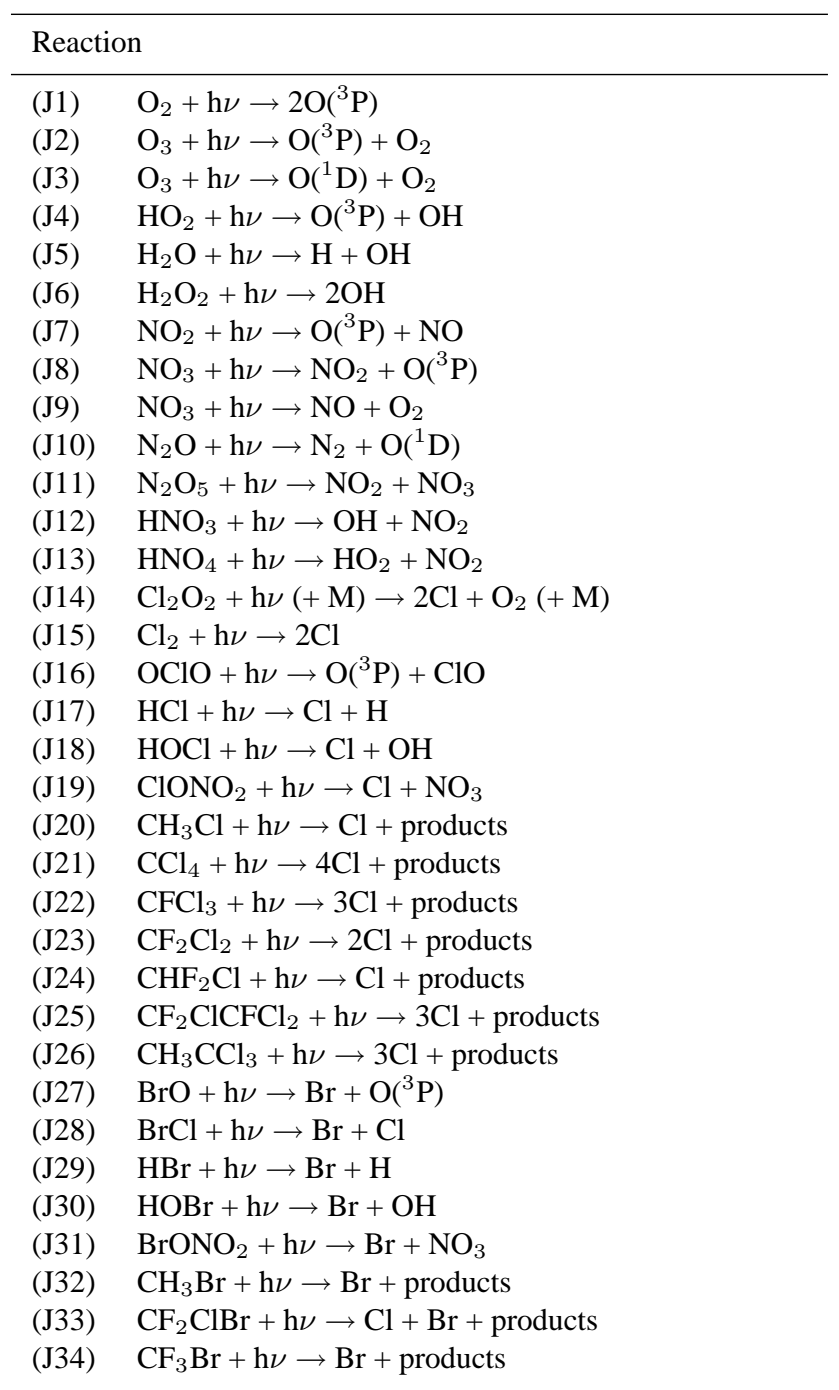

The term "products" represents constituents which are not considered in the present study.

of hydrogen, chlorine and bromine radicals. These source gases (marked by superscript $a$ in Table 1) are assumed to be unaffected by transport and chemistry. Constant latitudeheight distributions are taken into account for these compounds (see below). In order to minimize the numerical stiffness of the differential equations describing the chemical system, several highly reactive species, with chemical life times much smaller than transport timescales, are grouped into the families $\mathrm{O}_{x}:=\mathrm{O}\left({ }^{1} \mathrm{D}\right)+\mathrm{O}\left({ }^{3} \mathrm{P}\right)+\mathrm{O}_{3}, \mathrm{NO}_{x}:=\mathrm{NO}+\mathrm{NO}_{2}$, $\mathrm{HO}_{x}:=\mathrm{H}+\mathrm{OH}+\mathrm{HO}_{2}, \mathrm{ClO}_{x}:=\mathrm{Cl}+\mathrm{ClO}$ and $\mathrm{BrO}_{x}:=\mathrm{Br}+\mathrm{BrO}$. The continuity equations for the transported species are solved using the operator splitting technique. A semiimplicit method is employed to calculate the chemical contributions to concentration changes:

$n_{i}(t+\Delta t)=\left(n_{i}(t)+P_{i} \Delta t\right) /\left(1+\left[L_{i} / n_{i}(t)\right] \Delta t\right)$,

where $n_{i}$ is the concentration of species $i, P_{i}$ and $L_{i}$ are the chemical production and loss rates of species $i$, respec- 


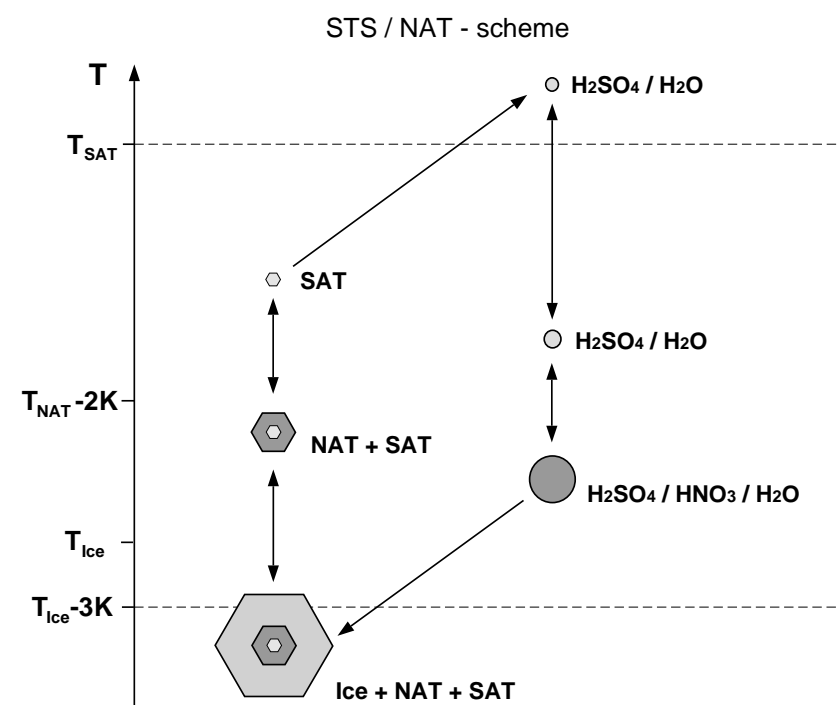

Fig. 1. Schematic overview of the particle types and the phase transition pathways considered in the standard version of the model (STS/NAT-scheme, see Sect. 2.3.1 for details).

tively, and $\Delta t$ is the chemical time step which is chosen as $\Delta t=225 \mathrm{~s}$ in the current model version. Since Eq. (1) is not necessarily mass conserving, a scaling procedure is applied which adjusts the total mass of nitrogen, chlorine and bromine atoms contained in a respective grid box to the values encountered before chemical integration. Assuming steady-state, the concentrations of the short-lived nontransported constituents at time $t+\Delta t$ are determined from the concentrations evaluated by Eq. (1).

The chemical mechanism includes 34 photolytic reactions, 114 gas-phase collision reactions and 6 heterogeneous reactions on liquid binary $\mathrm{H}_{2} \mathrm{SO}_{4} / \mathrm{H}_{2} \mathrm{O}$ and ternary $\mathrm{H}_{2} \mathrm{SO}_{4} / \mathrm{HNO}_{3} / \mathrm{H}_{2} \mathrm{O}$ solution aerosols, as well as NAT, sulfuric acid tetrahydrate (SAT) and ice particles. The set of reactions and the rate coefficients considered are listed in Tables 2,3 and 4 .

The rate coefficients of the photodissociation reactions are evaluated from a precalculated look-up table (G. Brasseur, personal communication, 1993) which includes the needed photolysis rates dependent on solar zenith angle, altitude, ozone column above the considered location and surface albedo. The methodology for derivation of the photolysis constants was described, for instance, by Brasseur et al. (1990) or Granier and Brasseur (1992). Several updates have been made to the absorption cross sections of the considered species, including the temperature dependence of the $\mathrm{HNO}_{3}$ (Rattigan et al., 1992) and the $\mathrm{ClONO}_{2}$ (Burkholder et al., 1994) cross sections. The photodissociation of bromine compounds was added to the model considering absorption cross sections, as recommended by DeMore et al. (1997). The adsorption cross sections of $\mathrm{HOBr}$ and $\mathrm{HBr}$ were chosen according to Orlando and Burkholder (1995) and Goodeve and Taylor (1935), respectively. The rate coefficients of the gas phase collision reactions are chosen according to De-
More et al. (1997) with the exceptions of reactions (R48), (R54), (R56) and (R72) which are treated following the recommendations of Baulch et al. (1981). The rates of the heterogeneous reactions are determined in analogy to the work of Hendricks et al. (1999) taking into account possible diffusion limitation of gas-to-particle mass fluxes. The uptake coefficients are evaluated as described in Table 4. The calculation of the surface area concentrations and characteristic sizes of the respective aerosol and PSC particles is described in Sect. 2.3.

The initial concentrations of the non-bromine containing chemical trace constituents were chosen according to the results of 2-D simulations performed by Brasseur et al. (1990). The concentrations of bromine compounds were initialized using the vertical profiles of bromine constituent concentrations calculated with a 1-D model by Krüger and Fabian (1986). The total abundances of inorganic chlorine and bromine compounds were adjusted to "present-day" conditions as simulated with the global AER 2-D model (D. K. Weisenstein, personal communication, 1997), resulting in total upper stratospheric concentrations of $3.2 \mathrm{ppbv}$ and 19.0 pptv, respectively. For a description of the AER model see, for instance, Weisenstein et al. (1996). In order to simulate stratospheric ozone distributions encountered during real episodes, model ozone was initialized using UARS-MLS data (see above).

\subsection{The microphysical module}

The COMMA microphysical module enables the evaluation of microphysical parameters relevant for the simulation of reactive and nonreactive uptake of trace constituents on and in stratospheric aerosol and PSC particles. Volume concentrations, surface area concentrations and characteristic sizes of liquid binary $\mathrm{H}_{2} \mathrm{SO}_{4} / \mathrm{H}_{2} \mathrm{O}$ and ternary $\mathrm{H}_{2} \mathrm{SO}_{4} / \mathrm{HNO}_{3} / \mathrm{H}_{2} \mathrm{O}$ solution aerosols as well as NAT, SAT and ice particles are evaluated. A schematic overview of the particle types and phase transition pathways considered in the standard version of the module (STS/NAT-scheme, Sect. 2.3.1) is displayed in Fig. 1. In addition to the standard microphysical scheme, two alternative PSC formation schemes are employed for the present study (Sect. 2.3.2).

\subsubsection{The STS/NAT-scheme}

The composition and volume concentration of liquid particles are calculated from modelled $\mathrm{H}_{2} \mathrm{SO}_{4}, \mathrm{HNO}_{3}, \mathrm{H}_{2} \mathrm{O}$ and temperature employing the method developed by Carslaw et al. (1995). The liquid aerosol surface area concentration as well as the liquid particle sizes which are key parameters controlling the rates of heterogeneous processes are inferred from the volume concentration assuming a unimodal lognormal size distribution. A total particle number concentration of $N=10 \mathrm{~cm}^{-3}$ and a geometric standard deviation of $\sigma=2$ are considered as size distribution parameters typical for the lower stratospheric background aerosol (Hofmann, 1990; Deshler et al., 1993). The initial spatial distri- 
Table 3. Gas phase reactions included in the model. Rate constants for first- and second-order reactions are given in units of $\mathrm{s}^{-1}$ and molecules ${ }^{-1} \mathrm{~cm}^{3} \mathrm{~s}^{-1}$, respectively. Rate constants for third-order reactions are given as effective second-order rate constants in units of molecules ${ }^{-1} \mathrm{~cm}^{3} \mathrm{~s}^{-1}$

\begin{tabular}{|c|c|c|}
\hline \multicolumn{2}{|c|}{ Reaction } & \multirow{2}{*}{$\begin{array}{l}\text { Rate constant } \\
1.8 \times 10^{-11} \exp (110 / \mathrm{T})\end{array}$} \\
\hline (R1) & $\mathrm{O}\left({ }^{1} \mathrm{D}\right)+\mathrm{N}_{2} \rightarrow \mathrm{O}\left({ }^{3} \mathrm{P}\right)+\mathrm{N}_{2}$ & \\
\hline (R2) & $\mathrm{O}\left({ }^{1} \mathrm{D}\right)+\mathrm{O}_{2} \rightarrow \mathrm{O}\left({ }^{3} \mathrm{P}\right)+\mathrm{O}_{2}$ & $3.2 \times 10^{-11} \exp (70 / \mathrm{T})$ \\
\hline (R3) & $\mathrm{O}\left({ }^{1} \mathrm{D}\right)+\mathrm{O}_{3} \rightarrow 2 \mathrm{O}_{2}$ & $1.2 \times 10^{-10}$ \\
\hline (R4) & $\mathrm{O}\left({ }^{3} \mathrm{P}\right)+\mathrm{O}\left({ }^{3} \mathrm{P}\right)+\mathrm{M} \rightarrow \mathrm{O}_{2}+\mathrm{M}$ & $4.7 \times 10^{-33}[\mathrm{M}](\mathrm{T} / 300 .)^{-2.0}$ \\
\hline (R5) & $\mathrm{O}\left({ }^{3} \mathrm{P}\right)+\mathrm{O}_{2}+\mathrm{M} \rightarrow \mathrm{O}_{3}+\mathrm{M}$ & $6.0 \times 10^{-34}[\mathrm{M}](\mathrm{T} / 300 .)^{-2.3}$ \\
\hline (R6) & $\mathrm{O}\left({ }^{3} \mathrm{P}\right)+\mathrm{O}_{3} \rightarrow 2 \mathrm{O}_{2}$ & $8.0 \times 10^{-12} \exp (-2060 / \mathrm{T})$ \\
\hline (R7) & $\mathrm{O}\left({ }^{1} \mathrm{D}\right)+\mathrm{H}_{2} \mathrm{O} \rightarrow 2 \mathrm{OH}$ & $2.2 \times 10^{-10} \mathrm{~T}-10$ \\
\hline (R8) & $\mathrm{O}\left({ }^{1} \mathrm{D}\right)+\mathrm{H}_{2} \rightarrow \mathrm{OH}+\mathrm{H}$ & $1.1 \times 10^{-10}$ \\
\hline (R9) & $\mathrm{H}+\mathrm{O}_{3} \rightarrow \mathrm{OH}+\mathrm{O}_{2}$ & $1.4 \times 10^{-10} \exp (-470 / \mathrm{T})$ \\
\hline (R10) & $\mathrm{H}+\mathrm{O}_{2}+\mathrm{M} \rightarrow \mathrm{HO}_{2}+\mathrm{M}$ & $f\left(k_{0}, k_{\infty}\right), k_{0}=5.7 \times 10^{-32}(\mathrm{~T} / 300)^{-1.6}, k_{\infty}=7.5 \times 10^{-11}$ \\
\hline$(\mathrm{R} 11)$ & $\mathrm{H}+\mathrm{HO}_{2} \rightarrow 2 \mathrm{OH}$ & $7.3 \times 10^{-11}$ \\
\hline$(\mathrm{R} 12)$ & $\mathrm{OH}+\mathrm{O}\left({ }^{3} \mathrm{P}\right) \rightarrow \mathrm{H}+\mathrm{O}_{2}$ & $2.2 \times 10^{-11} \exp (120 / \mathrm{T})$ \\
\hline (R13) & $\mathrm{OH}+\mathrm{OH} \rightarrow \mathrm{H}_{2} \mathrm{O}+\mathrm{O}\left({ }^{3} \mathrm{P}\right)$ & $4.2 \times 10^{-12} \exp (-240 / \mathrm{T})$ \\
\hline (R14) & $\mathrm{OH}+\mathrm{OH}+\mathrm{M} \rightarrow \mathrm{H}_{2} \mathrm{O}_{2}+\mathrm{M}$ & $f\left(k_{0}, k_{\infty}\right), k_{0}=6.2 \times 10^{-31}(\mathrm{~T} / 300)^{-1.0}, k_{\infty}=2.6 \times 10^{-11}$ \\
\hline$(\mathrm{R} 15)$ & $\mathrm{OH}+\mathrm{H}_{2} \mathrm{O}_{2} \rightarrow \mathrm{H}_{2} \mathrm{O}+\mathrm{HO}_{2}$ & $2.9 \times 10^{-12} \exp (-160 / \mathrm{T})$ \\
\hline (R16) & $\mathrm{OH}+\mathrm{H}_{2} \rightarrow \mathrm{H}_{2} \mathrm{O}+\mathrm{H}$ & $5.5 \times 10^{-12} \exp (-2000 / \mathrm{T})$ \\
\hline (R17) & $\mathrm{OH}+\mathrm{O}_{3} \rightarrow \mathrm{HO}_{2}+\mathrm{O}_{2}$ & $1.6 \times 10^{-12} \exp (-940 / \mathrm{T})$ \\
\hline (R18) & $\mathrm{OH}+\mathrm{HO}_{2} \rightarrow \mathrm{H}_{2} \mathrm{O}+\mathrm{O}_{2}$ & $4.8 \times 10^{-11} \exp (250 / \mathrm{T})$ \\
\hline (R19) & $\mathrm{HO}_{2}+\mathrm{O}\left({ }^{3} \mathrm{P}\right) \rightarrow \mathrm{OH}+\mathrm{O}_{2}$ & $3.0 \times 10^{-11} \exp (200 / \mathrm{T})$ \\
\hline (R20) & $\mathrm{HO}_{2}+\mathrm{O}_{3} \rightarrow \mathrm{OH}+2 \mathrm{O}_{2}$ & $1.1 \times 10^{-14} \exp (-500 / \mathrm{T})$ \\
\hline (R21) & $\mathrm{HO}_{2}+\mathrm{HO}_{2} \rightarrow \mathrm{H}_{2} \mathrm{O}_{2}+\mathrm{O}_{2}$ & $2.3 \times 10^{-13} \exp (600 / \mathrm{T})$ \\
\hline (R22) & $\mathrm{HO}_{2}+\mathrm{HO}_{2}+\mathrm{M} \rightarrow \mathrm{H}_{2} \mathrm{O}_{2}+\mathrm{O}_{2}+\mathrm{M}$ & $1.7 \times 10^{-33}[\mathrm{M}] \exp (1000 . / \mathrm{T})$ \\
\hline (R23) & $\mathrm{H}_{2} \mathrm{O}_{2}+\mathrm{O}\left({ }^{3} \mathrm{P}\right) \rightarrow \mathrm{HO}_{2}+\mathrm{OH}$ & $1.4 \times 10^{-12} \exp (-2000 / \mathrm{T})$ \\
\hline (R24) & $\mathrm{CH}_{4}+\mathrm{OH} \rightarrow \mathrm{H}_{2} \mathrm{O}+$ products & $2.65 \times 10^{-12} \exp (-1800 / \mathrm{T})$ \\
\hline (R25) & $\mathrm{CH}_{4}+\mathrm{O}\left({ }^{1} \mathrm{D}\right) \rightarrow \mathrm{OH}+$ products & $1.125 \times 10^{-10}$ \\
\hline (R26) & $\mathrm{N}_{2} \mathrm{O}+\mathrm{O}\left({ }^{1} \mathrm{D}\right) \rightarrow \mathrm{N}_{2}+\mathrm{O}_{2}$ & $4.9 \times 10^{-11}$ \\
\hline (R27) & $\mathrm{N}_{2} \mathrm{O}+\mathrm{O}\left({ }^{1} \mathrm{D}\right) \rightarrow 2 \mathrm{NO}$ & $6.7 \times 10^{-11}$ \\
\hline (R28) & $\mathrm{N}_{2}+\mathrm{O}\left({ }^{1} \mathrm{D}\right)+\mathrm{M} \rightarrow \mathrm{N}_{2} \mathrm{O}+\mathrm{M}$ & $3.5 \times 10^{-37}[\mathrm{M}](\mathrm{T} / 300 .)^{-0.6}$ \\
\hline$(\mathrm{R} 29)$ & $\mathrm{NO}+\mathrm{O}_{3} \rightarrow \mathrm{NO}_{2}+\mathrm{O}_{2}$ & $2.0 \times 10^{-12} \exp (-1400 / \mathrm{T})$ \\
\hline (R30) & $\mathrm{NO}+\mathrm{O}\left({ }^{3} \mathrm{P}\right)+\mathrm{M} \rightarrow \mathrm{NO}_{2}+\mathrm{M}$ & $f\left(k_{0}, k_{\infty}\right), k_{0}=9.0 \times 10^{-32}(\mathrm{~T} / 300)^{-1.5}, k_{\infty}=3.0 \times 10^{-11}$ \\
\hline (R31) & $\mathrm{NO}+\mathrm{HO}_{2} \rightarrow \mathrm{OH}+\mathrm{NO}_{2}$ & $3.5 \times 10^{-12} \exp (250 / \mathrm{T})$ \\
\hline (R32) & $\mathrm{NO}+\mathrm{NO}_{3} \rightarrow 2 \mathrm{NO}_{2}$ & $1.5 \times 10^{-11} \exp (170 / \mathrm{T})$ \\
\hline (R33) & $\mathrm{NO}_{2}+\mathrm{O}\left({ }^{3} \mathrm{P}\right) \rightarrow \mathrm{NO}+\mathrm{O}_{2}$ & $6.5 \times 10^{-12} \exp (120 / \mathrm{T})$ \\
\hline (R34) & $\mathrm{NO}_{2}+\mathrm{O}\left({ }^{3} \mathrm{P}\right)+\mathrm{M} \rightarrow \mathrm{NO}_{3}+\mathrm{M}$ & $f\left(k_{0}, k_{\infty}\right), k_{0}=9.0 \times 10^{-32}(\mathrm{~T} / 300)^{-2.0}, k_{\infty}=2.2 \times 10^{-11}$ \\
\hline$(\mathrm{R} 35)$ & $\mathrm{NO}_{2}+\mathrm{O}_{3} \rightarrow \mathrm{NO}_{3}+\mathrm{O}_{2}$ & $1.2 \times 10^{-13} \exp (-2450 / \mathrm{T})$ \\
\hline (R36) & $\mathrm{NO}_{2}+\mathrm{H} \rightarrow \mathrm{OH}+\mathrm{NO}$ & $4.0 \times 10^{-10} \exp (-340 / \mathrm{T})$ \\
\hline (R37) & $\mathrm{NO}_{2}+\mathrm{OH}+\mathrm{M} \rightarrow \mathrm{HNO}_{3}+\mathrm{M}$ & $f\left(k_{0}, k_{\infty}\right), k_{0}=2.5 \times 10^{-30}(\mathrm{~T} / 300)^{-4.4}, k_{\infty}=1.6 \times 10^{-11}(\mathrm{~T} / 300)^{-1.7}$ \\
\hline (R38) & $\mathrm{NO}_{2}+\mathrm{HO}_{2}+\mathrm{M} \rightarrow \mathrm{HNO}_{4}+\mathrm{M}$ & $f\left(k_{0}, k_{\infty}\right), k_{0}=1.8 \times 10^{-31}(\mathrm{~T} / 300)^{-3.2}, k_{\infty}=4.7 \times 10^{-12}(\mathrm{~T} / 300)^{-1.4}$ \\
\hline (R39) & $\mathrm{HNO}_{4}+\mathrm{M} \rightarrow \mathrm{HO}_{2}+\mathrm{NO}_{2}+\mathrm{M}$ & $k_{R 38} /\left(2.1 \times 10^{-27} \exp (10900 / \mathrm{T})\right)$ \\
\hline (R40) & $\mathrm{NO}_{2}+\mathrm{NO}_{3}+\mathrm{M} \rightarrow \mathrm{N}_{2} \mathrm{O}_{5}+\mathrm{M}$ & $f\left(k_{0}, k_{\infty}\right), k_{0}=2.2 \times 10^{-30}(\mathrm{~T} / 300)^{-3.9}, k_{\infty}=1.5 \times 10^{-12}(\mathrm{~T} / 300)^{-0.7}$ \\
\hline (R41) & $\mathrm{N}_{2} \mathrm{O}_{5}+\mathrm{M} \rightarrow \mathrm{NO}_{3}+\mathrm{NO}_{2}+\mathrm{M}$ & $k_{R 40} /\left(2.7 \times 10^{-27} \exp (11000 / \mathrm{T})\right)$ \\
\hline (R42) & $\mathrm{NO}_{3}+\mathrm{O}\left({ }^{3} \mathrm{P}\right) \rightarrow \mathrm{NO}_{2}+\mathrm{O}_{2}$ & $1.0 \times 10^{-11}$ \\
\hline (R43) & $\mathrm{NO}_{3}+\mathrm{OH} \rightarrow \mathrm{NO}_{2}+\mathrm{HO}_{2}$ & $2.2 \times 10^{-11}$ \\
\hline (R44) & $\mathrm{NO}_{3}+\mathrm{HO}_{2} \rightarrow \mathrm{HNO}_{3}+\mathrm{O}_{2}$ & $1.5 \times 10^{-12}$ \\
\hline (R45) & $\mathrm{HNO}_{3}+\mathrm{OH} \rightarrow \mathrm{NO}_{3}+\mathrm{H}_{2} \mathrm{O}$ & $\begin{array}{l}k_{1}+k_{2} /\left(1+k_{2} / k_{3}\right), k_{1}=7.2 \times 10^{-15} \exp (785 . / \mathrm{T}), k_{2}=1.9 \times 10^{-33}[\mathrm{M}] \exp (725 . / \mathrm{T}) \\
k_{3}=4.1 \times 10^{-16} \exp (1440 . / \mathrm{T})\end{array}$ \\
\hline (R46) & $\mathrm{HNO}_{4}+\mathrm{OH} \rightarrow \mathrm{NO}_{2}+\mathrm{H}_{2} \mathrm{O}+\mathrm{O}_{2}$ & $1.3 \times 10^{-12} \exp (380 / \mathrm{T})$ \\
\hline (R47) & $\mathrm{Cl}+\mathrm{O}_{3} \rightarrow \mathrm{ClO}+\mathrm{O}_{2}$ & $2.9 \times 10^{-11} \exp (-260 / \mathrm{T})$ \\
\hline (R48) & $\mathrm{Cl}+\mathrm{OH} \rightarrow \mathrm{HCl}+\mathrm{O}\left({ }^{3} \mathrm{P}\right)$ & $9.8 \times 10^{-12} \exp (-2860 / \mathrm{T})$ \\
\hline (R49) & $\mathrm{Cl}+\mathrm{HO}_{2} \rightarrow \mathrm{HCl}+\mathrm{O}_{2}$ & $1.8 \times 10^{-11} \exp (170 / \mathrm{T})$ \\
\hline (R50) & $\mathrm{Cl}+\mathrm{HO}_{2} \rightarrow \mathrm{OH}+\mathrm{ClO}$ & $4.1 \times 10^{-11} \exp (-450 / \mathrm{T})$ \\
\hline (R51) & $\mathrm{Cl}+\mathrm{H}_{2} \rightarrow \mathrm{HCl}+\mathrm{H}$ & $3.7 \times 10^{-11} \exp (-2300 / \mathrm{T})$ \\
\hline (R52) & $\mathrm{Cl}+\mathrm{CH}_{4} \rightarrow \mathrm{HCl}+$ products & $1.1 \times 10^{-11} \exp (-1400 / \mathrm{T})$ \\
\hline (R53) & $\mathrm{Cl}+\mathrm{H}_{2} \mathrm{O}_{2} \rightarrow \mathrm{HCl}+\mathrm{HO}_{2}$ & $1.1 \times 10^{-11} \exp (-980 / \mathrm{T})$ \\
\hline (R54) & $\mathrm{Cl}+\mathrm{H}_{2} \mathrm{O} \rightarrow \mathrm{HCl}+\mathrm{OH}$ & $2.79 \times 10^{-11} \exp (-8670 / \mathrm{T})$ \\
\hline (R55) & $\mathrm{Cl}+\mathrm{NO}_{3} \rightarrow \mathrm{ClO}+\mathrm{NO}_{2}$ & $2.4 \times 10^{-11}$ \\
\hline (R56) & $\mathrm{Cl}+\mathrm{Cl}+\mathrm{M} \rightarrow \mathrm{Cl}_{2}+\mathrm{M}$ & $6.14 \times 10^{-34}[\mathrm{M}] \exp (906 / \mathrm{T})$ \\
\hline (R57) & $\mathrm{Cl}+\mathrm{OClO} \rightarrow 2 \mathrm{ClO}$ & $3.4 \times 10^{-11} \exp (160 / \mathrm{T})$ \\
\hline (R58) & $\mathrm{Cl}+\mathrm{HOCl} \rightarrow \mathrm{Cl}_{2}+\mathrm{OH}$ & $6.0 \times 10^{-13} \exp (-130 / \mathrm{T})$ \\
\hline
\end{tabular}


Table 3. (continued)

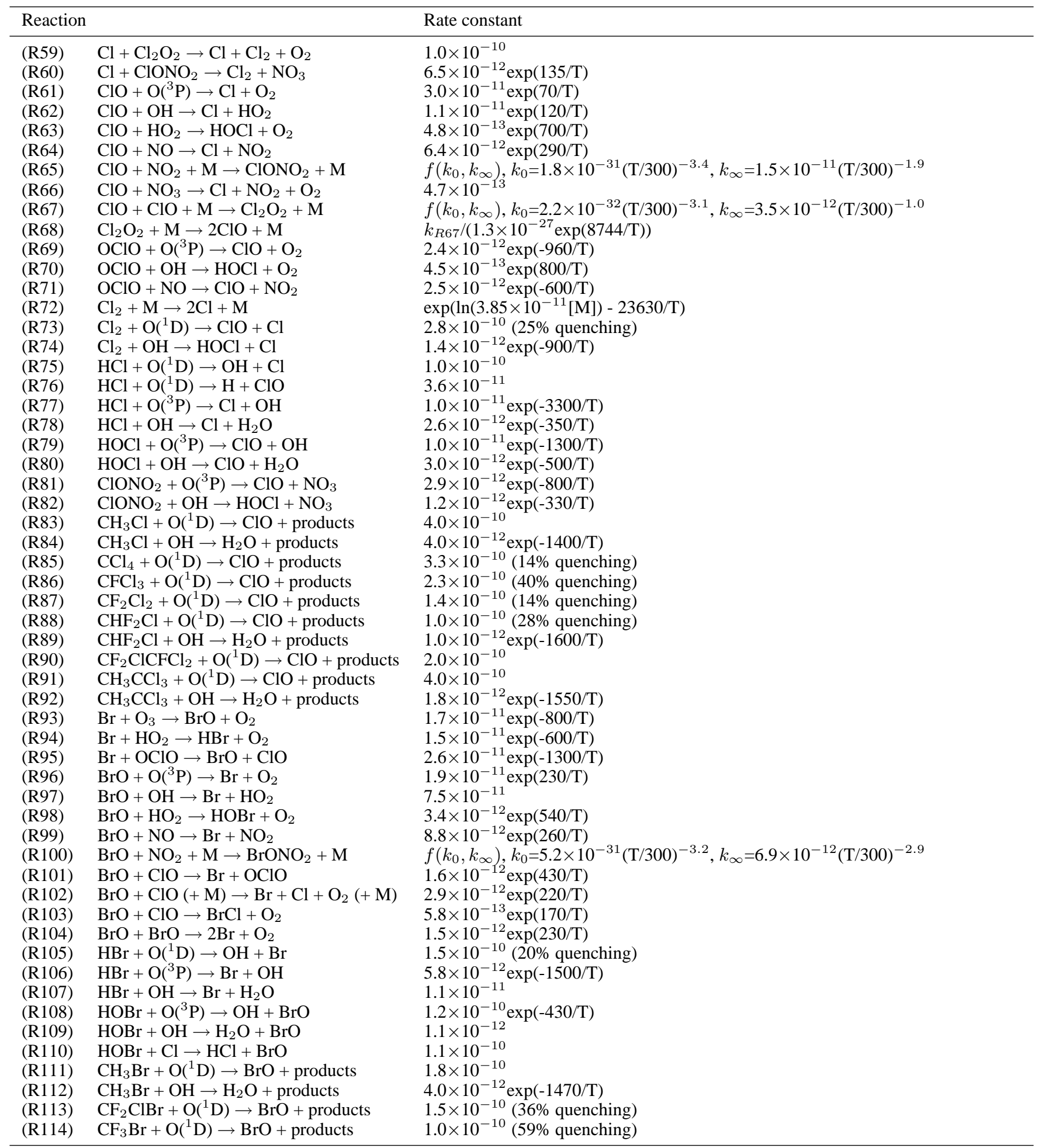

$\mathrm{M} \in\left\{\mathrm{N}_{2}, \mathrm{O}_{2}\right\}$. For third-order reactions, $f\left(k_{0}, k_{\infty}\right)$ has to be evaluated according to DeMore et al. (1997):

$f\left(k_{0}, k_{\infty}\right)=\left(k_{0}[\mathrm{M}] /\left(1+k_{0}[\mathrm{M}] / k_{\infty}\right)\right) \times 0.6^{\left(1+\left(\log _{10}\left(k_{0}[\mathrm{M}] / k_{\infty}\right)\right)^{2}\right)^{-1}}$. The term "products" represents

constituents which are not considered in the present study. 
Table 4. Heterogeneous reactions included in the model

\begin{tabular}{|c|c|c|c|c|c|}
\hline \multicolumn{2}{|c|}{ Reaction } & \multicolumn{4}{|l|}{ Uptake coefficient } \\
\hline & & & NAI & & \\
\hline (H1) & $\mathrm{N}_{2} \mathrm{O}_{5}+\mathrm{H}_{2} \mathrm{O} \rightarrow 2 \mathrm{HNO}_{3}$ & $0.1^{a}$ & $0.0003^{d}$ & $0.006^{e}$ & $0.01^{d}$ \\
\hline$(\mathrm{H} 2)$ & $\mathrm{ClONO}_{2}+\mathrm{H}_{2} \mathrm{O} \rightarrow \mathrm{HOCl}+\mathrm{HNO}_{3}$ & $f\left(T, p_{\mathrm{H}_{2} \mathrm{O}}, p_{\mathrm{HCl}}\right)^{b, c}$ & $f\left(T, p_{\mathrm{H}_{2} \mathrm{O}}\right)^{e, f}$ & $f\left(T, p_{\mathrm{H}_{2} \mathrm{O}}\right)^{h, f}$ & $0.3^{i}$ \\
\hline (H3) & $\mathrm{ClONO}_{2}+\mathrm{HCl} \rightarrow \mathrm{Cl}_{2}+\mathrm{HNO}_{3}$ & $f\left(T, p_{\mathrm{H}_{2} \mathrm{O}}, p_{\mathrm{HCl}}\right)^{b, c}$ & $f\left(T, p_{\mathrm{H}_{2} \mathrm{O}}, p_{\mathrm{HCl}}\right)^{e, f}$ & $f\left(T, p_{\mathrm{H}_{2} \mathrm{O}}\right)^{h, f}$ & $f\left(T, p_{\mathrm{HCl}}\right)^{j}$ \\
\hline (H4) & $\mathrm{HOCl}+\mathrm{HCl} \rightarrow \mathrm{Cl}_{2}+\mathrm{H}_{2} \mathrm{O}$ & $f\left(T, p_{\mathrm{H}_{2} \mathrm{O}}, p_{\mathrm{HCl}}\right)^{b, c}$ & $f\left(T, p_{\mathrm{H}_{2} \mathrm{O}}, p_{\mathrm{HCl}}\right)^{g, f}$ & - & $f\left(T, p_{\mathrm{HCl}}\right)^{k}$ \\
\hline (H5) & $\mathrm{BrONO}_{2}+\mathrm{H}_{2} \mathrm{O} \rightarrow \mathrm{HOBr}+\mathrm{HNO}_{3}$ & $f\left(T, p_{\mathrm{H}_{2} \mathrm{O}}\right)^{b}$ & - & - & - \\
\hline (H6) & $\mathrm{HOBr}+\mathrm{HCl} \rightarrow \mathrm{BrCl}+\mathrm{H}_{2} \mathrm{O}$ & $f\left(T, p_{\mathrm{H}_{2} \mathrm{O}}, p_{\mathrm{HCl}}\right)^{b, c}$ & - & - & - \\
\hline
\end{tabular}

${ }^{a}$ DeMore et al. (1997); ${ }^{b}$ as described by Hendricks et al. (1999); ${ }^{c} H_{\mathrm{HCl}}$ for ternary solutions from Luo et al. (1995); ${ }^{d} \mathrm{Hanson}$ and Ravishankara (1993a); ${ }^{e}$ Hanson and Ravishankara (1993b); ${ }^{f}$ Carslaw et al. (1997) (“scheme 1 "); ${ }^{g}$ Abbatt and Molina (1992); ${ }^{h}$ Zhang et al. (1994); ${ }^{i}$ Hanson and Ravishankara (1991); ${ }^{j}$ as described by Drdla et al. (1993), data from Leu (1988) and Hanson and Mauersberger (1990); ${ }^{k} \gamma=0.3 \times \gamma(\mathrm{H} 3) / \gamma_{\max }(\mathrm{H} 3)\left(\gamma\right.$ as recommended by De More et al. (1997), but with $\left(T, p_{\mathrm{HCl}}\right)$-dependence as $\left.\gamma(\mathrm{H} 3)\right)$

bution of sulfate mass is derived applying the inverse of the procedure described above to aerosol surface area concentrations as recommended by the WMO (1992) for stratospheric background aerosol conditions which can be assumed for the considered winter (Thomason et al., 1997).

It is assumed that formation of solid particles is initiated by the freezing of supercooled ternary solution particles at temperatures of $3 \mathrm{~K}$ below the ice frost point $T_{\text {ice }}$ (Koop et al., 1995) in order to form ice crystals. The ice volume concentration is calculated assuming thermodynamic equilibrium. Taking into account an ice particle number concentration of $0.01 \mathrm{~cm}^{-3}$ (e.g. Dye et al., 1992), the ice particle surface area concentration is evaluated with the simplifying assumption of ice particles showing spherical geometry and a monodisperse size distribution. Since NAT can nucleate heterogeneously on ice surfaces (Koop et al., 1997a, 1997b), it is assumed that NAT is incorporated into the ice particles during the freezing process. The NAT volume concentration is inferred from thermodynamic equilibrium constraints using the vapor pressure data provided by Hanson and Mauersberger (1988).

Mechanisms of SAT formation in the stratosphere are presently not fully understood. It is suggested that SAT forms by the heterogeneous freezing of sulfuric acid on ice particles rather than by homogeneous freezing processes (Koop et al., 1997a, 1997b). However, there is presently little evidence for SAT in the stratosphere (Carslaw et al., 1999). Hence, we assume that only a portion of the liquid particles are involved in the freezing processes. In the model simulations, 1 liquid particle per cubic centimeter is consumed by the freezing process described above and is incorporated as SAT into ice crystals. The coexistence of the remaining liquid sulfate aerosols and the solid particles fulfills thermodynamic stability requirements (Koop et al., 1997a). The number concentration of liquid particles involved in the freezing processes was chosen in correspondence to the respective SAT or NAT particle number concentration: a value of $1 \mathrm{~cm}^{-3}$ is generally considered as the particle number concentration of stratospheric crystalline hydrates (NAT or SAT). This is primarily motivated by the in situ measurements by Dye et al. (1992) performed in the Arctic lower stratosphere. Dye et al. (1992) found NAT particle number concentrations of $2-16 \mathrm{~cm}^{-3}$. They further discussed that these number concentrations are a factor of 2-3 higher than the condensation nuclei concentrations detected outside the PSCs. Since they could not explain this discrepancy, we decided to use the NAT and for consistency sake also the SAT number concentration of $1 \mathrm{~cm}^{-3}$ which shows a better correspondence to the condensation nuclei concentrations observed.

Ice particles are assumed to evaporate above $T_{\text {ice }}$ leaving NAT. The NAT surface area concentration is evaluated in analogy to that of ice particles, taking into account spherical geometry and a monodisperse size distribution. NAT is thermodynamically stable as long as the temperatures stay below the NAT equilibrium temperature $T_{\mathrm{NAT}}$ (Hanson and Mauersberger, 1988). If the temperature again falls below $T_{\text {ice, }}$ we assume that ice nucleates heterogeneously on the NAT surfaces (Koop et al., 1997a). If the temperature exceeds $T_{\mathrm{NAT}}, \mathrm{NAT}$ is assumed to evaporate and leave behind SAT. After preactivation of the SAT surface by an initial deposition of NAT, heterogeneous nucleation of NAT on SAT can occur at supersaturations $S_{\mathrm{NAT}}$ around 10 (corresponding to temperatures of $2-3 \mathrm{~K}$ below $T_{\mathrm{NAT}}$ ) (Zhang et al., 1996). In our simulations, SAT can act as an agent for NAT formation in the case of $S_{\mathrm{NAT}} \geq 10$. We further assume that SAT particles are transformed to liquid sulfate aerosols at temperatures above the SAT melting point $T_{\mathrm{SAT}}$ (Zhang et al., 1993).

\subsubsection{Alternative PSC schemes}

Two alternative PSC schemes can optionally be applied. First, a PSC scheme promoting solid particle formation is available. We will refer to this approach as the "NATscheme", where it is assumed that NAT can form whenever NAT equilibrium can be established $\left(T<T_{\mathrm{NAT}}\right)$. Hence, NAT can form at any NAT supersaturation, regardless of whether SAT is present. Thus, the NAT-scheme represents an upper limit for NAT particle occurrence. Similar to the STS/NAT-scheme, it is assumed in the NAT-scheme that a number of sulfate aerosols of $1 \mathrm{~cm}^{-3}$ is consumed by solid 


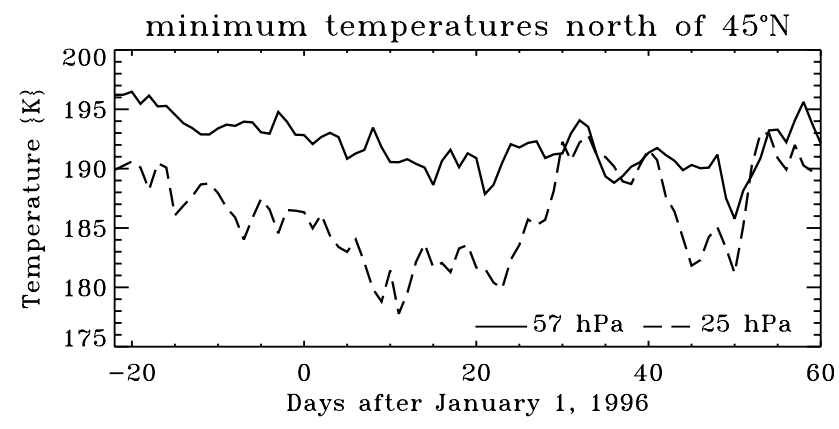

Fig. 2. Temporal change of model minimum temperatures within the area north of $45^{\circ} \mathrm{N}$. Data is presented for the time period between 10 December 1995, and 29 February 1996, and the model levels 57 and $25 \mathrm{hPa}$.

particle formation and that the rest of the sulfate aerosols remain liquid. As in the STS/NAT-scheme, ice nucleates on NAT particles if the temperature falls below $T_{\text {ice }}$ and NAT particles leave behind SAT after evaporation. Particle number concentrations of $10 \mathrm{~cm}^{-3}, 1 \mathrm{~cm}^{-3}$ and $0.01 \mathrm{~cm}^{-3}$ are assumed for liquid sulfate aerosols, NAT (or SAT) and ice particles, respectively. Second, a PSC scheme which we will refer to as the "STS-scheme" can be employed, where freezing processes are not considered. Hence, particles are generally in the liquid phase. PSC particles are formed by the uptake of $\mathrm{HNO}_{3}$ and water into liquid sulfuric acid aerosols. A number concentration of $10 \mathrm{~cm}^{-3}$ is assumed. The microphysical parameters relevant for chemical processing used when the NAT- or the STS-scheme is in consideration are evaluated in analogy to the STS/NAT-scheme (Sect. 2.3.1). For a summary of the PSC-schemes applied, see Table 5.

\section{Simulations}

As in a previous study by Günther and Baier (1998), the COMMA model was employed to simulate stratospheric dynamics and chemistry of the Arctic polar vortex during the winter 1995/96, which was characterized by comparatively low temperatures and an effective ozone loss (Manney et al., 1996a). In the present study, we focus in particular on the coldest period of that winter, which extended from midDecember 1995 to the end of February 1996. During this time, most of the PSC activity occurred. The model experiments were performed for the period between 10 December 1995, and 29 February 1996. The simulations were initialized using MLS ozone data as well as the results of a spin-up simulation covering the period between 25 November 1995, and 9 December 1995. The model spin-up provides chemical consistency and adjusts the chemical constituent spatial distributions to the dynamical conditions encountered at the start date of the main simulations. The initial trace gas concentrations in the spin-up model run were chosen as described in Sect. 2.2. In order to investigate the potential of different PSC types for chlorine activation and the corresponding ozone depletion, different model runs
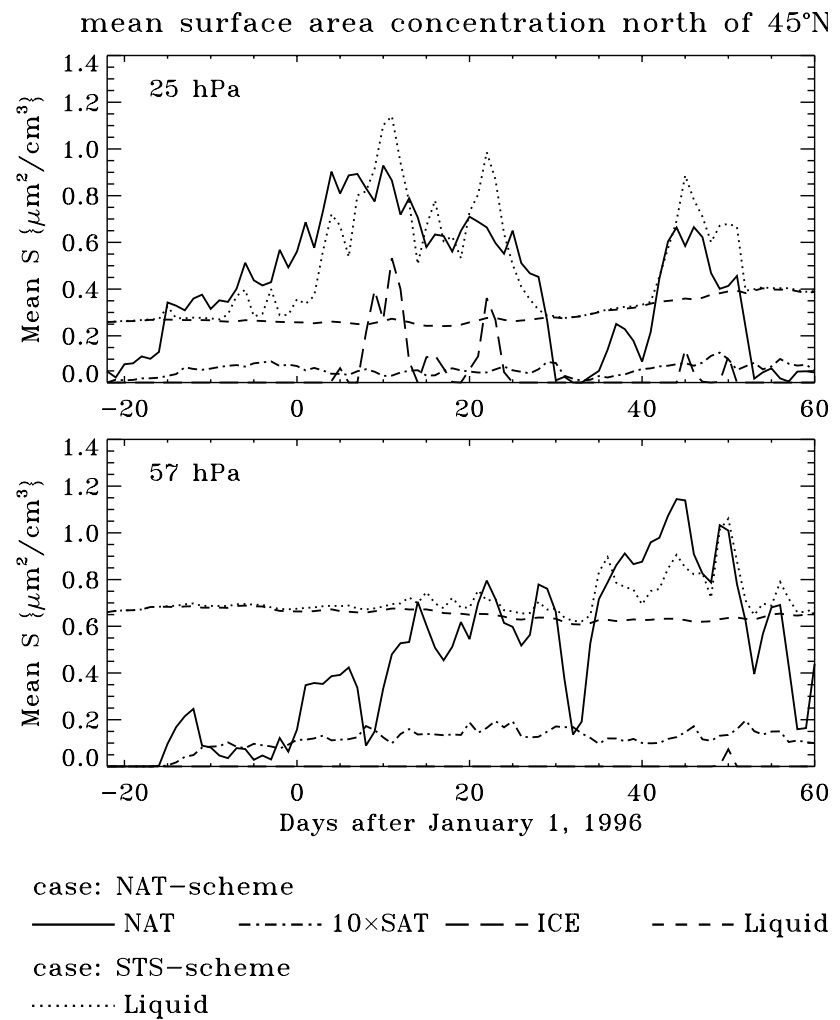

Fig. 3. Temporal change of particle surface area concentrations $\left(\mu \mathrm{m}^{2} \mathrm{~cm}^{-3}\right)$ averaged over the area north of $45^{\circ} \mathrm{N}$ on the model levels (bottom frame) $57 \mathrm{hPa}$ and (top frame) $25 \mathrm{hPa}$. Data is presented for the time period between 10 December 1995, and 29 February 1996, simulated in the model experiments performed with the NAT- and the STS-scheme, respectively.

were performed. First, the standard microphysical scheme (Sect. 2.3.1) called the STS/NAT-scheme was applied. Second, sensitivity studies were performed considering the STSscheme and the NAT-scheme described in Sect. 2.3.2. An additional model experiment where PSC formation is neglected and consequently, where heterogeneous chemistry is restricted to reactions on liquid binary sulfate aerosols is used as a reference simulation for evaluating the PSC impact on atmospheric chemistry. The corresponding microphysical scheme is referred to as the "BIN-scheme" (Table 5).

The temporal development of the model minimum temperatures occurring north of $45^{\circ} \mathrm{N}$ on the two coldest model levels, $57 \mathrm{hPa}$ (approximately $19 \mathrm{~km}$ altitude) and $25 \mathrm{hPa}$ (approximately $25 \mathrm{~km}$ altitude), is shown in Fig. 2. Since the model is driven by ECMWF analysis below $10 \mathrm{hPa}$ (Sect. 2.1), the data represents ECMWF temperatures interpolated on the model grid. The minimum temperature stays below $195 \mathrm{~K}$ during almost the entire simulated period at both model levels. Since $195 \mathrm{~K}$ approximately corresponds to the NAT formation threshold temperature, NAT particles potentially could occur during prolonged time periods. Ice particle formation was promoted on the $25 \mathrm{hPa}$ level due to very low temperatures, especially during January and mid- 
Table 5. PSC schemes applied (see text for details)

\begin{tabular}{ll}
\hline PSC scheme & Comments \\
\hline STS/NAT-scheme & standard PSC scheme (see Fig. 1) \\
NAT-scheme & solid particles generally present below $T_{\text {NAT }}$ \\
STS-scheme & no solid particle formation \\
BIN-scheme & liquid binary sulfate particles only \\
\hline
\end{tabular}

\section{February 1996.}

The temporal development of surface area concentrations of different particle types modelled employing the NAT- and the STS-scheme is presented in Fig. 3 for the $57 \mathrm{hPa}$ and the $25 \mathrm{hPa}$ level. The data was averaged over the domain north of $45^{\circ} \mathrm{N}$. A circumpolar averaging domain was chosen, rather than only the vortex area, in order to avoid a dependence of the results on the vortex area definition and to adequately include PSCs located at the vortex edge (occurring especially during the late winter). The threshold of $45^{\circ} \mathrm{N}$ was chosen since PSC activity as well as the related chlorine activation (see below) were almost totally restricted to areas north of that latitude. The simulation performed with the NAT-scheme demonstrates that the potential for NAT particle existence (NAT equilibrium conditions) was present at both pressure levels, especially during January and mid-February when the lowest temperatures occurred. Ice particles are formed in the NAT-scheme case preferently at $25 \mathrm{hPa}$ during January. The relatively large mean surface area concentration of liquid particles in the NAT-scheme simulation results from sulfate aerosols being omnipresent with significant concentrations throughout the area considered. The simulation with the STS-scheme which includes only liquid particles is represented by the dotted line. Large deviations from the modelled liquid aerosol surface area concentration obtained with NAT-scheme occur during mid-February at $57 \mathrm{hPa}$, and during January and mid-February at $25 \mathrm{hPa}$. This is a consequence of the effective uptake of $\mathrm{HNO}_{3}$ and water into liquid particles simulated in the STS-scheme model run for the coldest periods of the winter. The results presented in Fig. 3 reveal that occurrences of large liquid surface areas in the STS-case mostly are of a shorter duration when compared to the PSC events simulated in the NAT-case. Horizontal distributions of PSC surface area concentrations at 57 and $25 \mathrm{hPa}$, as simulated considering the NAT- and the STS-scheme are shown in Fig. 4. The results are presented for days of comparatively large surface area concentrations in both simulations. Since chlorine activation was most effective in January (see below), we focus in particular on that month. The characteristic difference between the two PSC types is that large surface area concentrations of liquid PSC particles in the simulation with the STS-scheme are restricted to smaller spatial areas compared to the areas covered by PSCs formed by solid particles in the NAT-scheme simulation. Similar to the work of Carslaw et al. (1997), it can be concluded that areas where NAT particles can potentially exist in equilibrium $\left(T<T_{\mathrm{NAT}}\right)$ appear to be significantly larger and occur over longer time periods compared to the areas showing conditions appropriate for large liquid particle formation.

In the simulations performed with the STS/NAT-scheme (not figured), solid particle occurrences are primarily restricted to the January $25 \mathrm{hPa}$ level, where model temperatures occasionally fall below the threshold of $T_{\text {ice }}-3 \mathrm{~K}$. This induces freezing of ternary solution droplets resulting in effective solid particle formation. As a consequence, PSCs encountered during January at $25 \mathrm{hPa}$ in the STS/NAT simulation are primarily composed of NAT or ice particles. The strong temperature increase occurring in late January at $25 \mathrm{hPa}$ leads to evaporation of these PSCs and subsequently to melting of SAT. Since model stratospheric temperatures stay primarily above $T_{\text {ice }}-3 \mathrm{~K}$ during February, solid PSC particle formation occurs only very sparsely during February in the STS/NAT case.

As a consequence of the PSC activity discussed above, an effective production of active chlorine is simulated. Chlorine activation was also observed during the winter 1995/96 by means of $\mathrm{ClO}$ measurements taken with the UARS-MLS instrument (Santee et al., 1996; Waters et al., 1996). In order to validate the model $\mathrm{ClO}$, a comparison with the MLS data was performed. Due to the large noise inherent in the MLS $\mathrm{ClO}$, a comparison of local $\mathrm{ClO}$ concentrations is difficult. Hence, similar to the work of Massie et al. (2000), we evaluated the temporal evolution of spatially averaged $\mathrm{ClO}$ data. Figure 5 shows the temporal development of MLS (version 4) and the model $\mathrm{ClO}$ averaged over the model levels located at 57 and $25 \mathrm{hPa}$. MLS ClO is plotted for the time periods available in the MLS data set (see below). Model results are presented for the simulations including PSC effects (the NAT-, the STS, and the STS/NAT-scheme simulation). For the same reasons as in the case of the particle surface area concentrations (Fig. 3), averages were calculated over the area northward of $45^{\circ} \mathrm{N}$. Data northward of $80^{\circ} \mathrm{N}$ was not included since this area was not covered by the MLS observations. In order to exclude inconsistencies caused by the diurnal variation of the $\mathrm{ClO}$ concentration, we only take into account daytime $\mathrm{ClO}$ which has the additional advantage that it can be taken as an approximation to the full extent of active chlorine. The MLS ClO data points considered were selected as recommended by Waters et al. (1996). Only those days of sufficient availability of daytime data points were taken into account. The error bars were calculated on the basis of the accuracies and the single profile precisions recommended by L. Froidevaux et al. (http://mls.jpl.nasa.gov; see also Massie et al., 2000).

The comparison reveals that the model results resemble the MLS data most of the time within the measurement error range. Strong deviations between the model and the observations occur especially during the end of January at $25 \mathrm{hPa}$ when averaged model $\mathrm{ClO}$ exceeds the upper limit of the MLS tolerance. Significant deviations also occur during February when the model tends to show larger $\mathrm{ClO}$ amounts at $25 \mathrm{hPa}$ and lower values at $57 \mathrm{hPa}$. However, these discrepancies primarily stay within the MLS error. Generally, the large noise of MLS ClO hampers a more quantitative evalu- 
NAT-scheme

solid particles

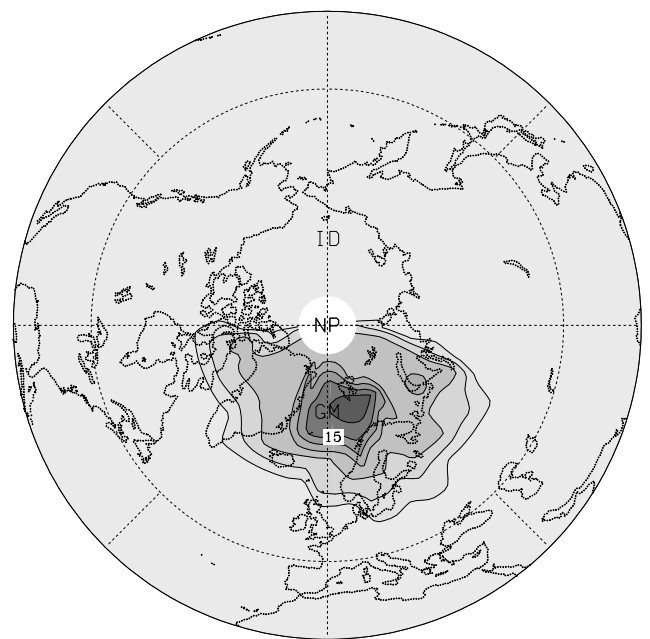

\section{STS-scheme}

liquid particles

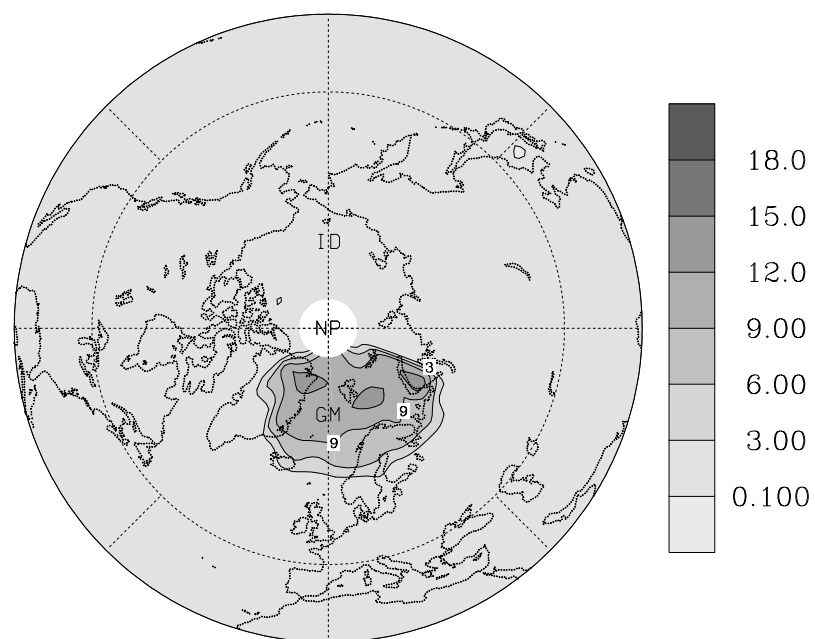

$25 \mathrm{hPa}, 12$ January 1996
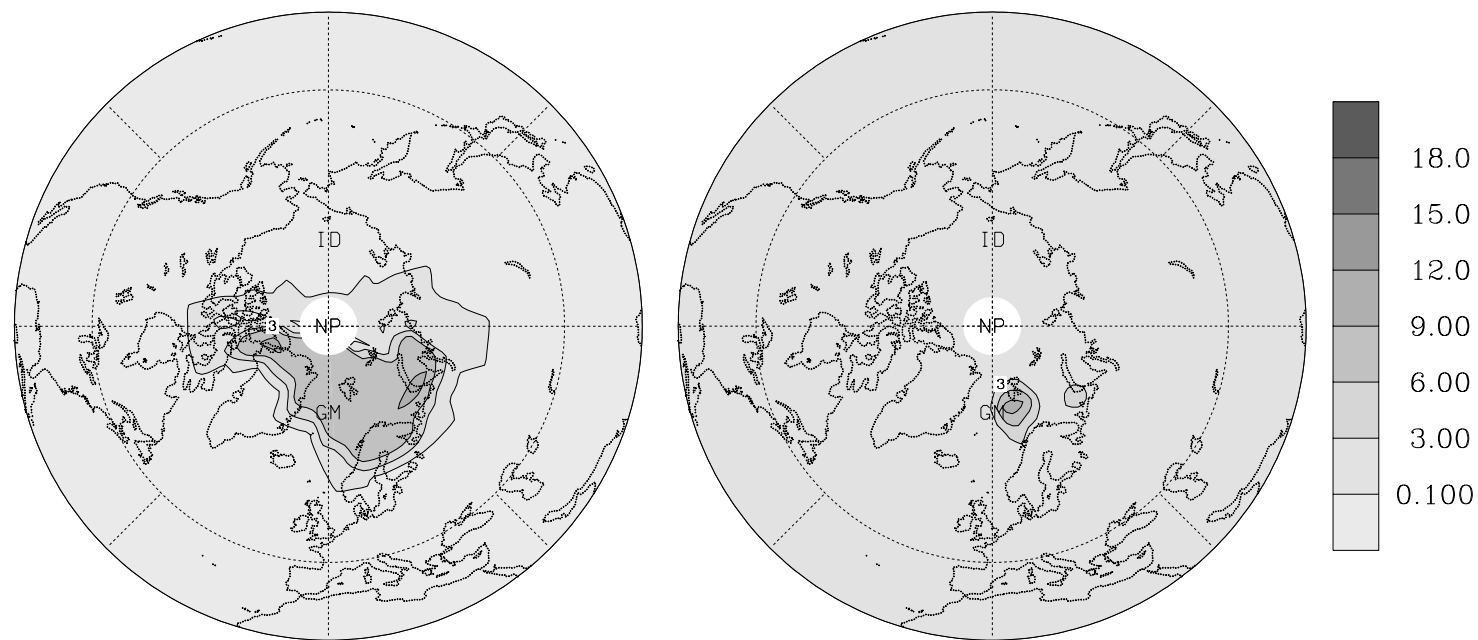

57 hPa, 22 January 1996

\section{surface area concentration $\left[\mu \mathrm{m}^{2} \mathrm{~cm}^{-3}\right.$ ]}

Fig. 4. Surface area concentration $\left(\mu \mathrm{m}^{2} \mathrm{~cm}^{-3}\right)$ of different particle types modelled for (top frames) the $25 \mathrm{hPa}$ and (bottom frames) the $57 \mathrm{hPa}$ levels. Results are shown for two selected days of January 1996 showing comparatively large PSC activity (57 hPa level on 22 January 1996, and $25 \mathrm{hPa}$ level on 12 January 1996). The left frames show the total solid particle surface area concentration (NAT, SAT and ice particles) modelled applying the NAT-scheme. The right frames present the surface area concentration of liquid particles simulated using the STS-scheme.

ation of the model quality. The comparison also suffers from large measurement gaps in the MLS data during the time period considered. The variation of model $\mathrm{ClO}$ caused by the assumption of different PSC microphysical schemes is small compared to the MLS error. Hence, the comparison of model ClO to MLS data can only be helpful in terms of a rough model validation, rather than in identifying the most realistic PSC microphysical code. It can be concluded that the model is able to reproduce observed chlorine activation in a qualitatively reasonable manner. Most of the time during MLS data availability, deviations between modelled and observed $\mathrm{ClO}$ stay within the MLS error range.

Compared to the model study by Massie et al. (2000) which focusses on chlorine activation during December 1995 and early January 1996, the COMMA simulations appear to show a less effective mid-December chlorine activation at 

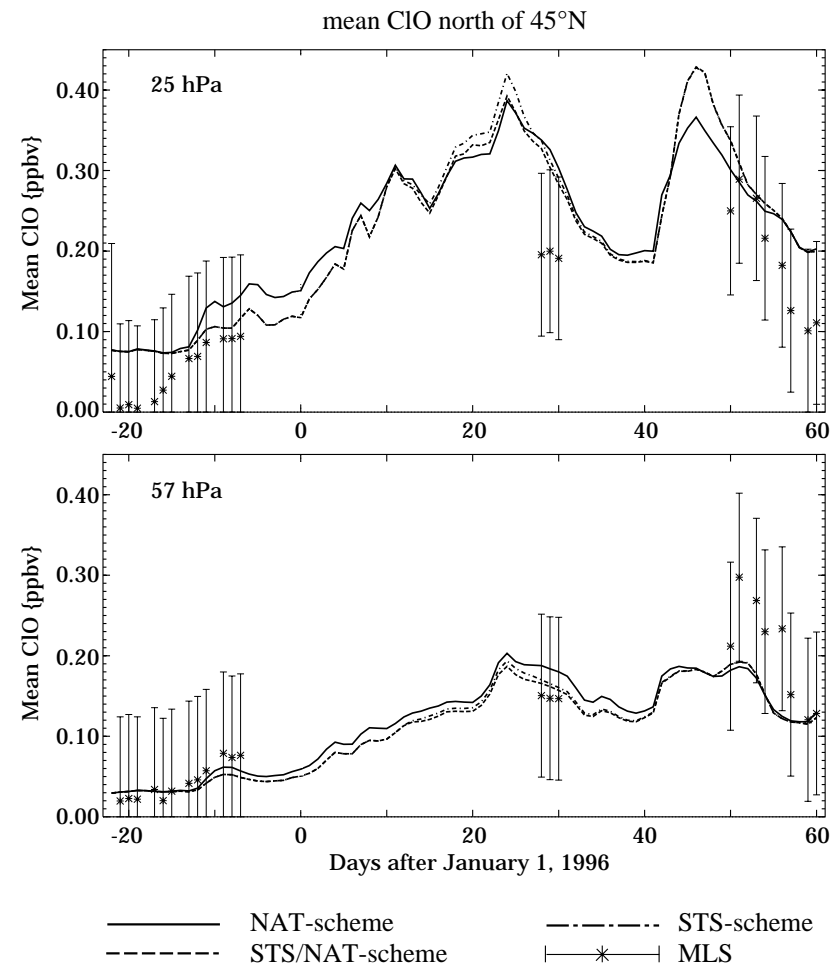

Fig. 5. Temporal change of the $\mathrm{ClO}$ mixing ratio (ppbv) averaged over the area between $45^{\circ} \mathrm{N}$ and $80^{\circ} \mathrm{N}$. Model results are shown as obtained with the COMMA model applying the NAT-, the STS- and the STS/NAT-scheme, respectively. For comparison, corresponding average $\mathrm{ClO}$ concentrations derived from UARS-MLS observational data as well as the potential MLS ClO errors are presented. Data is shown for the model levels (bottom frame) $57 \mathrm{hPa}$ and (top frame) $25 \mathrm{hPa}$ and the time period between 10 December 1995, and 29 February 1996. Only daytime $\mathrm{ClO}$ data is taken into account. See text for details.

lower stratospheric pressure levels. Compared to the MLS data, chlorine activation during mid-December is less effective at $57 \mathrm{hPa}$ in the COMMA simulations. In the results of Massie et al. obtained for 46 and $100 \mathrm{hPa}$, mean daytime $\mathrm{ClO}$ concentrations during mid-December are larger than corresponding MLS values. Since temperatures were very close to the type 1 PSC formation thresholds during this time period, the discrepancies between the two models may result from differences in the PSC microphysical representation and also from temperature differences between the U.K. Meteorological Office (UKMO) data used in the work of Massie et al. (2000) and the ECMWF data set employed here. Knudsen et al. (1996) compared ECMWF analysis data to balloon bourne measurements taken during the winter 1994/95 in the arctic vortex at pressure levels around $50 \mathrm{hPa}$. They found that ECMWF temperatures were on average $2.4 \mathrm{~K}$ higher compared to the in situ measurements. In a similar study by Manney et al. (1996b), average warm biases of UKMOanalyses of $0.5-1.9 \mathrm{~K}$ were calculated for different periods of the same winter. Hence, ECMWF temperatures appear to show a larger average warm bias compared to UKMO analy-
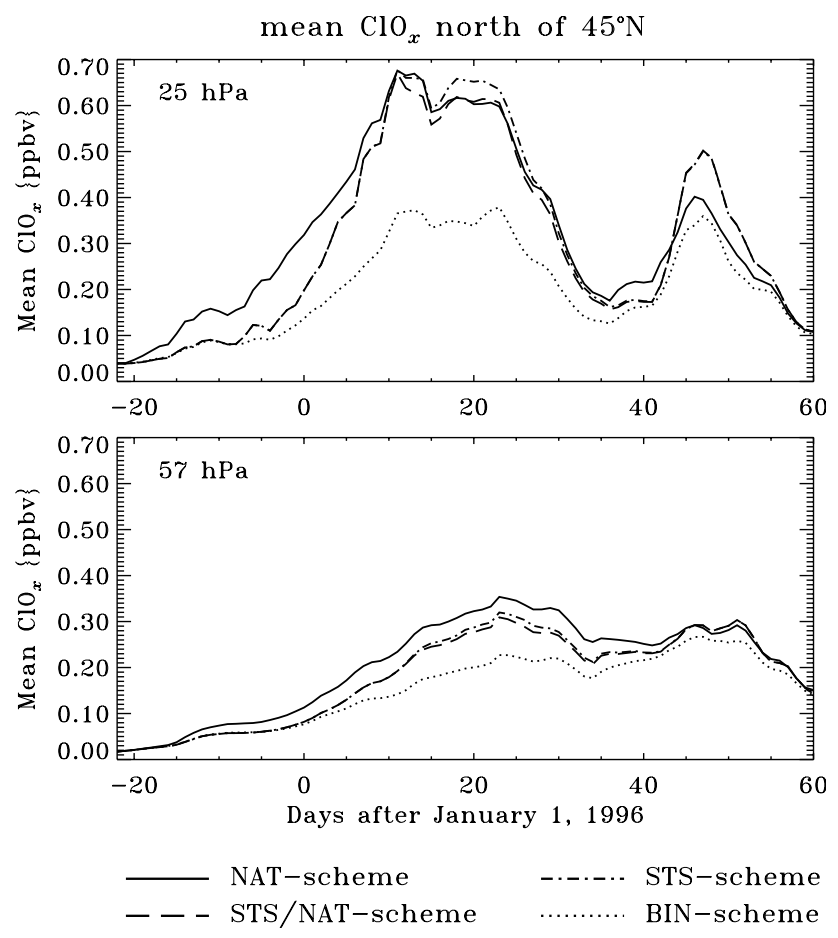

Fig. 6. Temporal change of the $\mathrm{ClO}_{x}(:=\mathrm{Cl}+\mathrm{ClO}+$ $2 \mathrm{Cl}_{2} \mathrm{O}_{2}+2 \mathrm{Cl}_{2}+\mathrm{HOCl}+\mathrm{OClO}$ ) mixing ratio (ppbv) averaged over the area north of $45^{\circ} \mathrm{N}$ on the model levels (bottom frame) $57 \mathrm{hPa}$ and (top frame) $25 \mathrm{hPa}$. Results are presented for the time period between 10 December 1995, and 29 February 1996, simulated in the model experiments performed with the NAT-, the STS-, the STS/NAT- and the BIN-scheme, respectively.

ses. Assuming that this is also the case for the winter 1995/96 data (Knudsen et al., further reported on an ECMWF warm bias of $1.8 \mathrm{~K}$ for January 1996), it would be consistent with the discrepancy in chlorine activation simulated by the different models.

The temporal change of $\mathrm{ClO}_{x}:=\mathrm{Cl}+\mathrm{ClO}+2 \mathrm{Cl}_{2} \mathrm{O}_{2}+$ $2 \mathrm{Cl}_{2}+\mathrm{HOCl}+\mathrm{OClO}$ simulated for the model levels $57 \mathrm{hPa}$ and $25 \mathrm{hPa}$ is shown in Fig. 6 (note that the definition of $\mathrm{ClO}_{x}$ used here differs from that used in Sect. 2.2). Compared to daytime $\mathrm{ClO}$ (Fig. 5), $\mathrm{ClO}_{x}$ has the advantage of consistently representing the full extent of chlorine activation at any time of the day. The use of daytime $\mathrm{ClO}$ was forced by the restriction of the MLS data set providing $\mathrm{ClO}$ as the only representative of active chlorine compounds. Figure 6 shows the results obtained with the NAT-, the STS-, the STS/NATand the BIN-scheme, respectively. Mixing ratios averaged over the region north of $45^{\circ} \mathrm{N}$ are presented. As discussed above, this averaging domain was chosen rather than only the vortex area, in order to also include PSC-induced perturbations located outside the vortex. The strong chlorine activation simulated for January and mid-February appears as the response to the PSC activity described above. Spatial distributions of $\mathrm{ClO}_{x}$ at 57 and $25 \mathrm{hPa}$ modelled with the NAT- and the STS-scheme for specific days of the mid- 

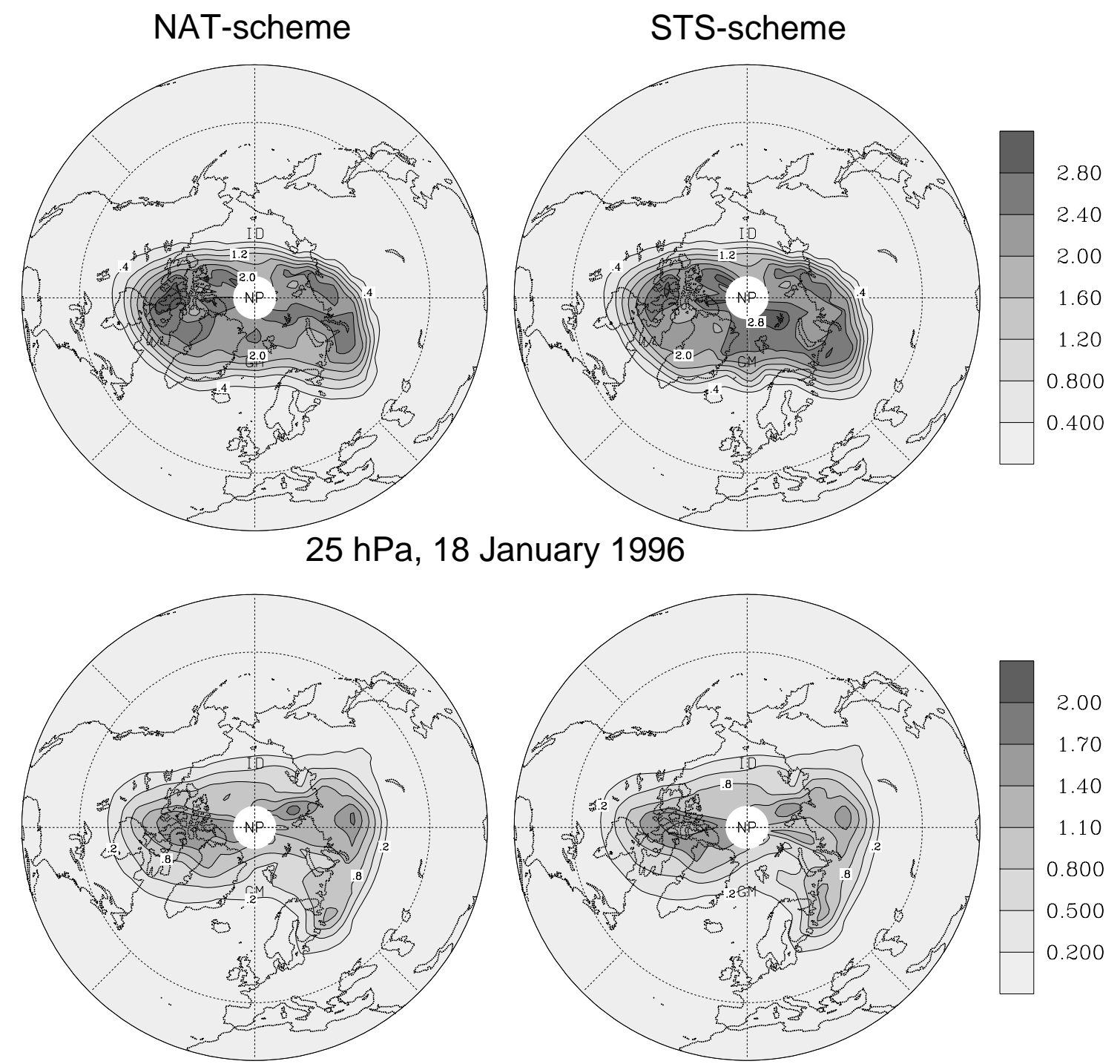

$57 \mathrm{hPa}, 23$ January 1996

\section{$\mathrm{ClO}_{x}[\mathrm{ppbv}]$}

Fig. 7. $\mathrm{ClO}_{x}\left(:=\mathrm{Cl}+\mathrm{ClO}+2 \mathrm{Cl}_{2} \mathrm{O}_{2}+2 \mathrm{Cl}_{2}+\mathrm{HOCl}+\mathrm{OClO}\right)$ mixing ratio (ppbv) modelled for (top frames) the $25 \mathrm{hPa}$ and (bottom frames) the $57 \mathrm{hPa}$ levels. Results are shown for two selected days of January 1996 showing comparatively large chlorine activation (57 hPa level on 23 January 1996, and $25 \mathrm{hPa}$ level on 18 January 1996). The left frames and right frames show data modelled applying the NAT- and the STS-scheme, respectively.

January period of maximum chlorine activation are displayed in Fig. 7. Both Figs. 6 and 7 reveal that the $\mathrm{ClO}_{x}$ concentrations obtained using the different PSC schemes can differ significantly. Maximum deviations in spatial mean $\mathrm{ClO}_{x}$ (Fig. 6) amount to 0.1 ppbv. Local differences (Fig. 7) up to $0.3 \mathrm{ppbv}(57 \mathrm{hPa})$ and $0.4 \mathrm{ppbv}(25 \mathrm{hPa})$ occur during the January period of maximum activation. Similar to the simulations of Massie et al. (2000), the most effective early winter chlorine activation is modelled with the NAT-scheme. This partly changes during January and late February, especially during the periods of very low temperatures at $25 \mathrm{hPa}$ when very high liquid particle surface area concentrations occurred in the STS-scheme experiment (see also discussion on ozone changes). It should be noted that, apart from these differences, the similarity between the different simulations is remarkable regarding the large contrasts in surface area concentrations modelled with the NAT- and the STS-scheme. An important reason for this is the compensation between two important effects which were already discussed by Carslaw et al. (1997): On the one hand, the most relevant heterogeneous reactions, especially $\mathrm{ClONO}_{2}+\mathrm{HCl}$, are faster on liquids compared to NAT (Ravishankara and Hanson, 1996). 
On the other hand, large surface area concentrations of liquid particles in the STS simulation are less frequent and are restricted to smaller areas when compared to the NAT surface area concentrations in the NAT-scheme case. It should be further noted that, in addition to PSC particles, binary sulfate aerosols also have the potential to induce strong chlorine activation. This is indicated by the BIN-scheme simulation and agrees with the work of Massie et al. (2000). Consistent with the above discussion on the modelled PSC surface area concentrations, the chlorine activation simulated for December and February using the STS/NAT-scheme is very similar to that modelled in the STS case. Due to the formation of solid particles in the STS/NAT simulation, the two scenarios diverge during January.

In order to assess the model quality with respect to the representation of stratospheric ozone distributions, we also compared the modelled ozone concentrations with UARSMLS data. Due to the comparatively long lifetime of ozone, the spatial structure of the model ozone fields is likely to be sensitive to model deficiencies, such as potential shortcomings in the representation of longer term trace gas transport. Hence, we compared modelled horizontal ozone distributions to corresponding MLS ozone fields. Since cumulative ozone loss is of particular relevance to polar stratospheric ozone depletion, special focus was given to the February ozone minimum which followed the strong January chlorine activation (Figs. 6 and 9). In order to evaluate the model quality for more than individual days, horizontal ozone distributions were averaged over a time period starting on 13 February, which is the first day with data available after the MLS turn-off from 2 to 12 February. Since the comparison is primarily addressing the assessment of minimum ozone concentrations, the averaging period ends on 20 February, which is the last day which is not impacted by model ozone recovery (see Fig. 9). Figure 8 shows the temporally averaged spatial distributions of ozone at $57 \mathrm{hPa}$ and $25 \mathrm{hPa}$ calculated from the model output (STS/NAT case) and the MLS data, respectively. The comparison reveals that model ozone deviates from the observations especially in the polar vortex area. While the ozone maximum covering the North Pacific and Northeast Asia is well represented in the simulation with only slightly larger concentrations and a slight northward shift compared to the MLS data, the model overpredicts the ozone abundance within the polar vortex. The deviation of the modelled polar vortex ozone concentrations from the corresponding MLS values typically ranges between $30 \%$ and $80 \%$ at $25 \mathrm{hPa}$, and between $20 \%$ and $50 \%$ at $57 \mathrm{hPa}$. These discrepancies exceed the MLS error which amounts to 10-20\% within the lower stratosphere. The overprediction of polar vortex ozone appears to be a common problem of stratospheric 3-D models and was discussed in many previous studies on ozone depletion in the Arctic winter stratosphere (e.g. Steil et al., 1998; Hansen and Chipperfield, 1999; Ruhnke et al., 1999). Potential reasons for this effect are possible underrepresentations of PSC processes in stratospheric models (e.g. the neglect of lee wave PSC (Hansen and Chipperfield, 1999) or the underestimation of denitri- fication (Sinnhuber et al., 2000)) as well as deficiencies of current global stratospheric 3-D models concerning the representation of vertical transport, especially inside the vortex (Steil et al., 1998). As introduced above, the present study is intended to provide a sensitivity analysis of the impact of the differences in PSC schemes on model stratospheric chemistry. Since the effect of ozone concentration on PSC microphysics and on the efficiency of the related heterogeneous reactions is small, the impact of overestimations in model ozone should not affect the general conclusions on the sensitivities considered.

The temporal development of the PSC-induced ozone change at 57 and $25 \mathrm{hPa}$, averaged over the model domain north of $45^{\circ} \mathrm{N}$ is highlighted in Fig. 9. In order to capture only the PSC effects, the ozone change was calculated from the differences between the NAT-, the STS-, and the STS/NAT-scheme simulations, respectively, and the model experiment only considering liquid binary sulfate aerosols (BIN-scheme). Ozone changes in the range of -0.02 to -0.04 ppmv calculated for the end of the simulated period appear to be small, due to the fact that the values are averaged over a domain which is only partially affected by ozone loss (local PSC-induced ozone deficits of up to $0.2 \mathrm{ppmv}$ are simulated). Another important reason is that ozone loss also occurs in the reference simulation including only binary sulfate aerosols (BIN-scheme).

A significant scattering in the spatial mean ozone change resulting from the differences in the PSC-schemes is modelled. Maximum deviations of around $10 \mathrm{ppbv}$ are simulated for mid-February. Apart from the conditions in late February at $25 \mathrm{hPa}$, the strongest ozone depletion is simulated in the case of the NAT-scheme experiment. This is due to the comparatively high December temperatures and the corresponding lack of large liquid particle surface area concentrations occuring in the STS- and the STS/NAT-scheme experiments when effective NAT particle formation already takes place in the NAT-scheme simulation. The consequence is a delay in chlorine activation and the resulting ozone loss in the liquid particle cases, which can also be found in the results of Brühl et al. (1997) obtained for the winter 1995/96. Due to similar conditions, ozone depletion rates modelled in the NAT-scheme experiment again exceed those of the STS- and the STS/NAT-scheme simulations in the beginning of February. As discussed above (see discussion on Fig. 3), significant solid particle occurrences in the STS/NAT case can be found only during January at $25 \mathrm{hPa}$. Hence, chlorine activation and the related ozone loss rates in the STS- and the STS/NAT-scheme experiments are nearly identical during December and February. Due to the January solid particle occurrence, the STS/NAT-scheme simulation shows a smaller ozone depletion rate compared to the STS case, especially during the second half of January. Hence, the STS/NAT simulation generally shows the smallest ozone depletion rather than representing an intermediate state between the STS- and the NAT-scheme model runs.

In mid-February, very low temperatures occurring at $25 \mathrm{hPa}$ promote an increase in the liquid particle surface 


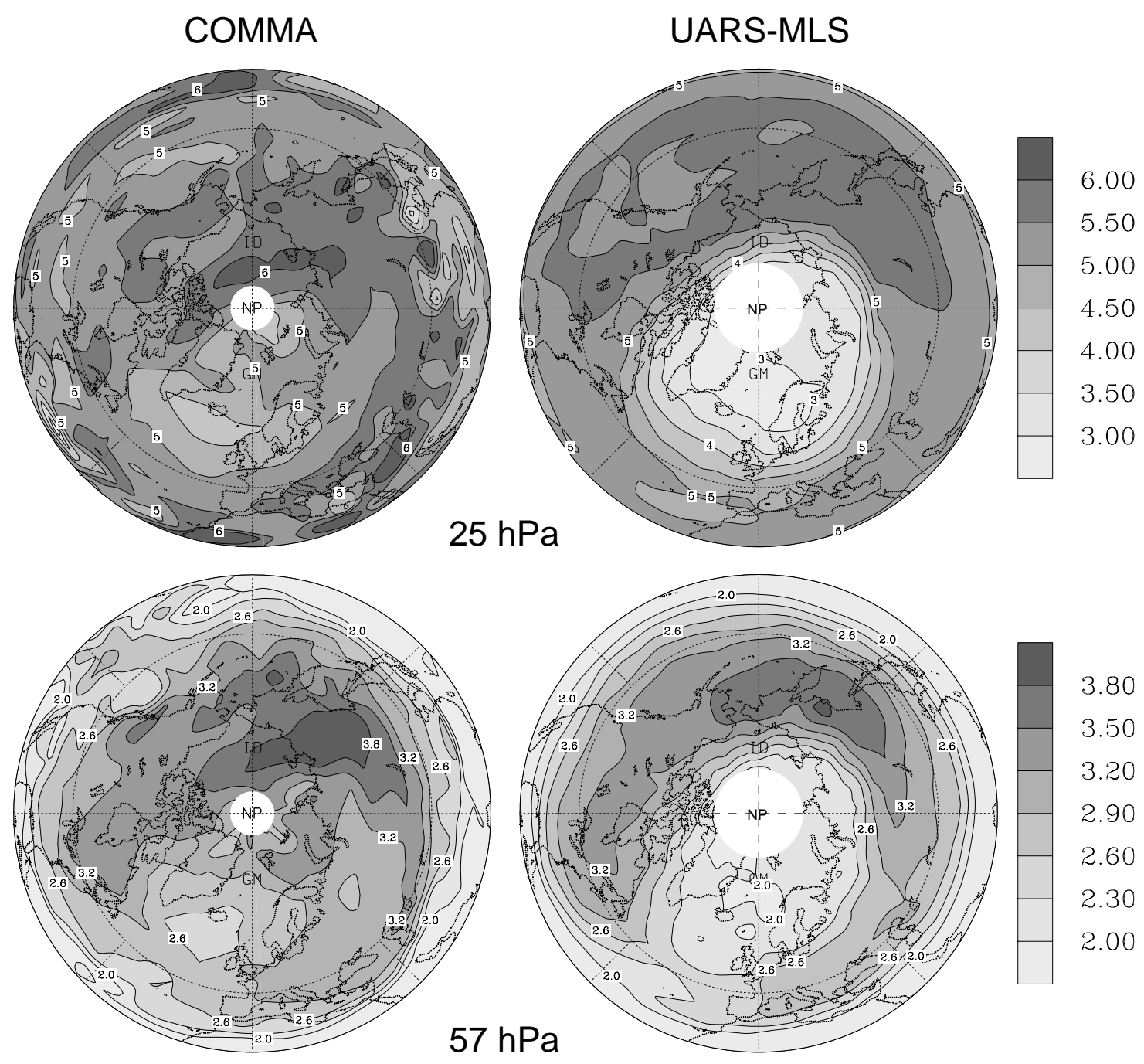

\section{$\mathrm{O}_{3}$ [ppmv ], 13 - 20 February 1996}

Fig. 8. Temporal mean ozone mixing ratio (ppmv) of the period between 13 and 20 February 1996, (left) calculated from the simulation using the STS/NAT-scheme and (right) derived from UARS-MLS data. Horizontal distributions are shown for (top frames) $25 \mathrm{hPa}$ and (bottom frames) $57 \mathrm{hPa}$.

area concentration and the related chlorine activation in the STS experiment (Figs. 3 and 6, top panels). This temperature decrease was not strong enough to cause effective ice formation in the NAT-scheme experiment, as was the case during the January periods of large liquid surface area occurrences. This results in a chlorine activation modelled with the STS-scheme largely exceeding that obtained using the NATscheme. As a consequence, late February ozone depletion at $25 \mathrm{hPa}$ modelled in the STS-scheme simulation increases to be slightly larger when compared to the NAT-scheme experiment. As already mentioned, February ozone depletion rates behave similarly in the STS/NAT case and the STS simulation. However, for the reasons discussed above, the resulting PSC-induced ozone deficit in the STS/NAT case does not exceed that modelled in the NAT-scheme simulation.
It should be noted that the assumptions on freezing conditions strongly impact the STS/NAT-scheme experiment. A threshold temperature of $3 \mathrm{~K}$ below the ice frost point is assumed for initial solid particle formation via freezing of liquid ternary solution droplets (Sect. 2.3). A higher freezing temperature may shift the results obtained with the STS/NAT-scheme towards those of the NAT-scheme simulation, as was the case in the Sessler et al. (1996) study. It should also be noted that the rate coefficients for heterogeneous reactions on NAT are calculated here following "scheme 1" suggested by Carslaw et al. (1997). The corresponding uptake coefficients can be taken as upper limits. Carslaw et al. also proposed a set of minimum likely uptake coefficients ("scheme 2") which was not taken into account here because, as pointed out in the Carslaw et al., study, 

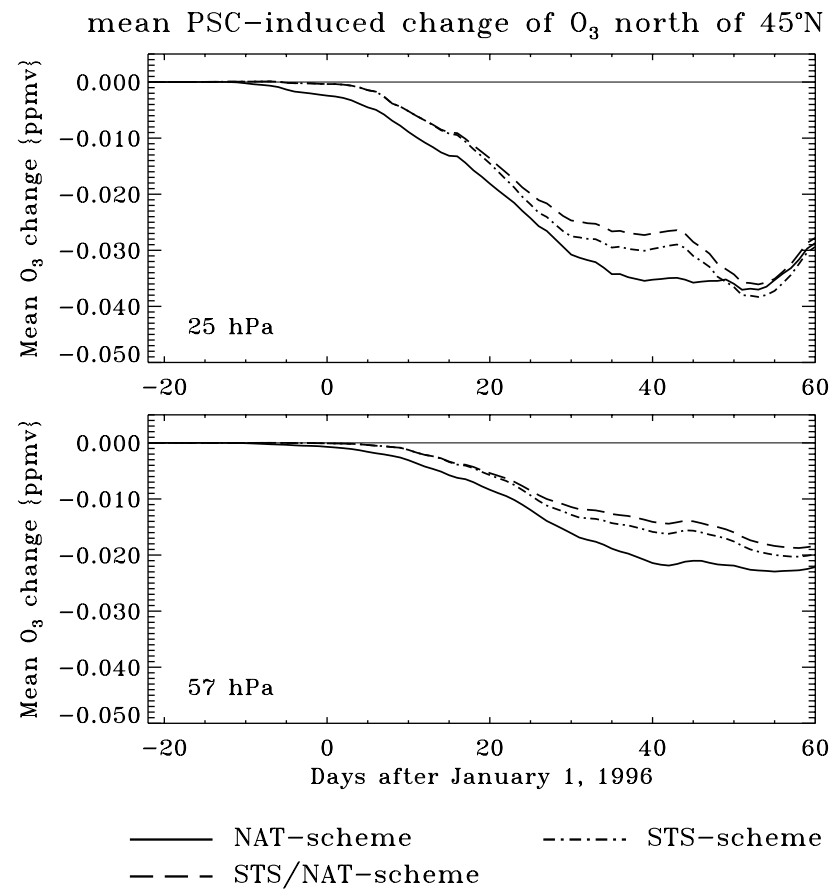

Fig. 9. Temporal change of the PSC-induced depletion of the ozone mixing ratio (ppmv) averaged over the area north of $45^{\circ} \mathrm{N}$ on the model levels (bottom frame) $57 \mathrm{hPa}$ and (top frame) $25 \mathrm{hPa}$. Results are presented for the time period between 10 December 1995, and 29 February 1996, calculated from the differences between the model experiments performed with the NAT-, the STS- and the STS/NAT-scheme, respectively, and the simulation where only liquid binary sulfate aerosols are considered (BIN-scheme).

ozone depletion in the winter $1994 / 95$ predicted on the basis of these coefficients, is less than that estimated from observations. An application of "scheme 2" in the present simulations may shift the results of the NAT-scheme simulation obtained for the December to mid-February period towards those of the STS-scheme experiment.

Horizontal distributions of ozone differences between the NAT-scheme model run and the STS-scheme simulation, as calculated for the $57 \mathrm{hPa}$ and the $25 \mathrm{hPa}$ pressure levels, are presented in Fig. 10. The results are shown for 13 February, when the effective ozone depletion induced by the large January chlorine activation has fully developed (Figs. 6 and 9), and for 25 February, when the spatial mean ozone deficit in the STS simulation exceeds that of the NAT-scheme experiment at $25 \mathrm{hPa}$ (Fig. 9). Regarding 13 February, application of the NAT-scheme results in up to $20 \mathrm{ppbv}$ lower ozone concentrations at both pressure levels when compared to the STS-scheme experiment. The maximum difference at $57 \mathrm{hPa}$ decreases to values around 15 ppbv on 25 February. Nevertheless, for the reasons discussed above, the difference between the two experiments is of opposite sign on 25 February at $25 \mathrm{hPa}$. Ozone depletion modelled in the STS-scheme simulation exceeds that calculated in the NAT experiment by typically around $15 \mathrm{ppbv}$ and locally up to $40 \mathrm{ppbv}$. This increase in ozone depletion in the STS case is the response to more than 1 ppbv larger mid-February $\mathrm{ClO}_{x}$ concentrations (not displayed) in the STS-scheme simulation when compared to the NAT-scheme experiment. Also the trajectory calculations of Brühl et al. (1997) suggest such an overturning in ozone depletion occurring in February 1996 in the Arctic stratosphere. Brühl et al. (1997) modelled strong similarities in ozone loss in the liquid and the solid particle scenarios occurring until mid-February. In late February, ozone depletion in the liquid particle case exceeds that modelled when PSC particles are assumed to be solid. The ozone difference between these two model runs amounts to about 100 ppbv at the end of February. Thus a larger difference is modelled when compared to the present study. However, it should be mentioned that the trajectory assumed by Brühl et al. (1997) is located somewhere in between the $25 \mathrm{hPa}$ and the $57 \mathrm{hPa}$ pressure levels considered in this study. Hence, the results of the trajectory calculations cannot directly be compared to the 3-D simulations performed here. Brühl et al. (1997) also emphasized that the results obtained with the assumption of idealized trajectories have to be taken as qualitative. Furthermore, discrepancies between trajectory calculations and 3-D model results can also be a consequence of the 3-D model deficiencies in vertical transport representation which were discussed above.

\section{Conclusions}

Simulations with a 3-D model were performed in order to investigate the impact of differences in PSC-microphysical schemes on the model chemistry of the winter Arctic stratosphere. The model calculations were carried out for the winter 1995/96. Results obtained for the model levels located at 57 and $25 \mathrm{hPa}$ were analysed. A comparison of simulations with a "NAT-scheme" and an "STS-scheme", where PSC particles are considered to be solid or liquid, respectively, suggests that, in the considered winter, areas where NAT and other solid particles could potentially exist in equilibrium $\left(T<T_{\mathrm{NAT}}\right)$ were significantly larger and occurred over longer time periods compared to the areas showing conditions appropriate for large liquid particle formation. These differences induce significant deviations in chlorine activation and the resulting ozone depletion modelled assuming the different PSC microphysical schemes. At maximum chlorine activation, which is modelled for January 1996, local deviations in $\mathrm{ClO}_{x}$ range up to 0.4 ppbv. At $57 \mathrm{hPa}$, the NATscheme simulation shows larger maximum $\mathrm{ClO}_{x}$ concentrations compared to the STS-scheme case, and maximum chlorine activation levels in the STS-scheme experiment are primarily larger at $25 \mathrm{hPa}$. However, the PSC-induced midFebruary ozone depletion resulting from the PSC activity during the mid-December to early February cold period is the largest in the solid particle case at both pressure levels. Even the corresponding ozone differences between the liquid and the solid particle experiments, which approach 20 ppbv, are quite similar at 25 and $57 \mathrm{hPa}$. These deviations in the midFebruary ozone deficit are induced primarily by a temporal 

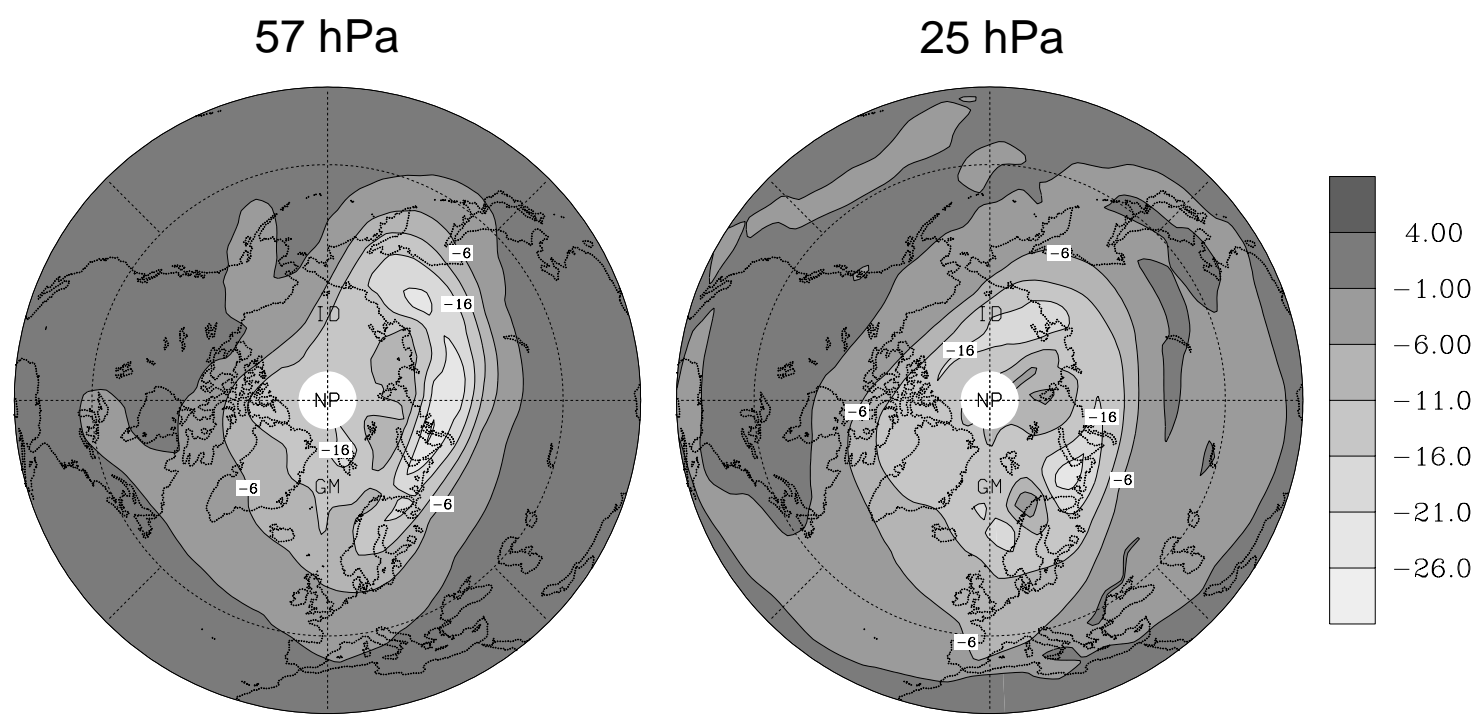

\section{February 1996}
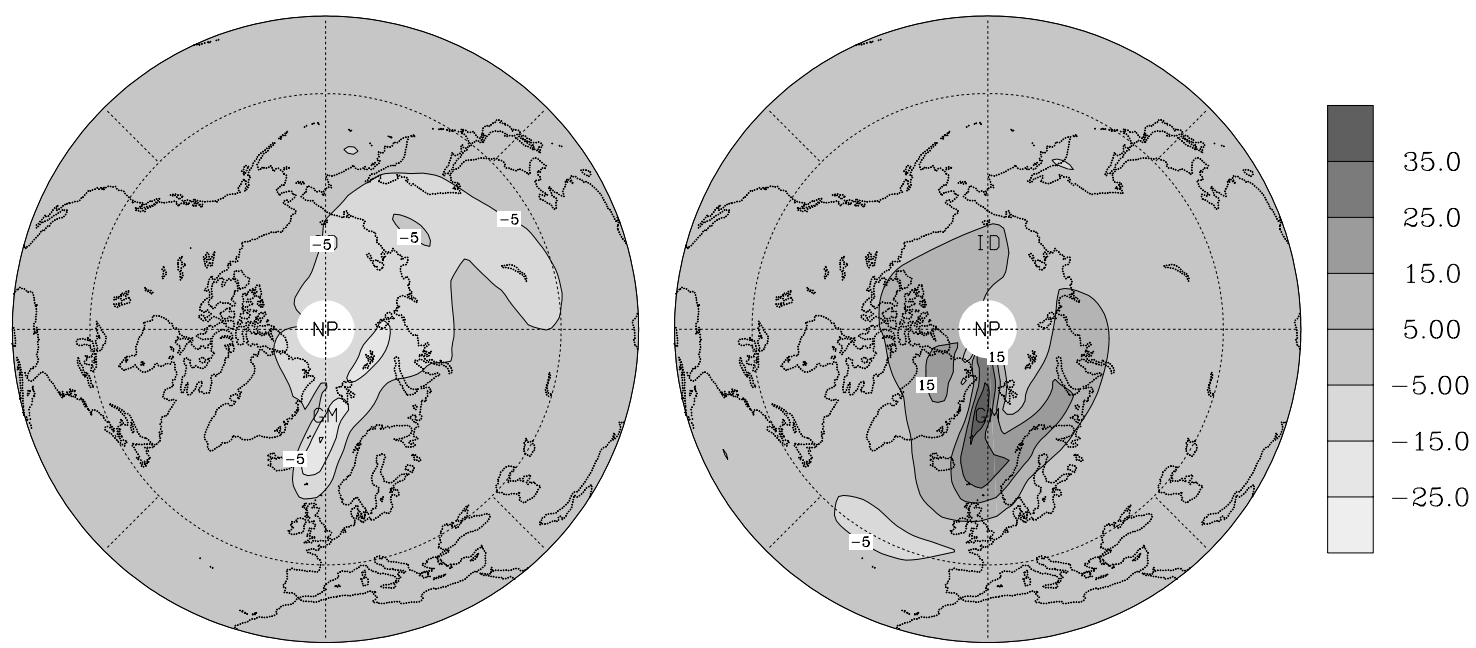

25 February 1996

\section{$\Delta \mathrm{O}_{3}$ [ ppbv ] (Difference: NAT-scheme - STS-scheme)}

Fig. 10. Difference in the ozone mixing ratio (ppbv) occurring between the simulations performed with the NAT- and the STS-scheme on (left) the $57 \mathrm{hPa}$ and (right) the $25 \mathrm{hPa}$ level. Results are presented obtained for (top panels) 13 February 1996, and (bottom panels) 25 February 1996.

delay in early winter chlorine activation in the STS case, caused by a lack of large liquid particle surface area concentrations in December 1995. When NAT particles are already present in the NAT-scheme case, temperatures are still too high to allow for the effective growth of liquid particles in the STS-scheme simulation. The largest differences in chlorine activation occurring between the two model experiments develop in mid-February at pressure levels around $25 \mathrm{hPa}$. Over large areas, temperatures decrease below the threshold of effective liquid particle $\mathrm{HNO}_{3}$ and water uptake. Due to the resulting large liquid particle surface area concentrations and the very efficient heterogeneous chemistry on liquid particles, effective chlorine activation occurs in the STS-scheme simulation. Since temperatures fall infrequently below $T_{\text {ice }}$ during mid-February and large NAT surface area concentrations are already present in the NAT-scheme experiment, a comparable increase in chlorine activation is not simulated in that case. Hence chlorine activation in the STS simulation strongly exceeds that modelled with the NAT-scheme. Maximum local deviations in $\mathrm{ClO}_{x}$ of up to $1.5 \mathrm{ppbv}$ are simulated. Consequently, ozone depletion is stronger in the STS model run under these conditions. For the end of February, maximum differences in the ozone mixing ratio of around 40 ppbv are modelled.

It should be noted that these differences in ozone concentration are significant but small relative to the large deviations 
in PSC surface area concentrations modelled in the two experiments. This is primarily due to the larger efficiency of the most relevant heterogeneous reactions on liquids when compared to NAT. This compensates for the smaller mean surface area concentrations of liquid PSCs. It should be further noted that the STS/NAT simulation, where solid as well as liquid PSCs can occur, does not generally represent an intermediate state between the STS- and the NAT-scheme experiments. The deviations of the STS/NAT simulation from the two other model runs are primarily controlled by the assumptions on freezing conditions. Thus, the freezing threshold temperature appears to be an important parameter which influences modelled stratospheric ozone depletion.

The results described above corroborate the findings of Brühl et al. (1997), who investigated stratospheric ozone depletion in the winter 1995/96 by means of trajectory-boxmodel calculations. Our general conclusions are also consistent with the trajectory-box simulations of other winters performed by Brühl et al. (1997) and Carslaw et al. (1997). However, maximum differences in ozone depletion caused by the assumptions about PSC particles being either liquid or solid are smaller in the 3-D simulations compared to the other studies.

In summary, differences in PSC-schemes can result in significant deviations in PSC-induced ozone depletion in the winter Arctic stratosphere simulated with stratospheric chemistry models. The largest differences between ozone depletion modelled assuming liquid or solid PSCs, respectively, can be expected when the following conditions can be encountered on large spatial scales and for prolonged time periods in the winter Arctic stratosphere. First, stratospheric temperatures stay below $T_{\mathrm{NAT}}$ but above the threshold of effective liquid particle growth. Second, temperatures stay significantly below this threshold but do not fall below the ice frost point.

Acknowledgement. We want to express our thanks to G. Brasseur (NCAR, now at MPI-M) for supplying the programs for precalculating the look-up table of photolysis rates. We are grateful to D. K. Weisenstein (AER Inc.) for providing AER 2-D data of $\mathrm{Br}_{y}$ and $\mathrm{Cl}_{y}$ concentrations. The UARS-MLS data was supplied by the British Atmospheric Data Centre (BADC) and the Jet Propulsion Laboratory (JPL). European Centre for Medium Range Weather Forecasts (ECMWF) global analysis data were used with permission of the German Weather Service (DWD). The present study was financially supported by the German Federal Ministry for Education, Science, Research and Technology (BMBF) under grant 01 LO9516/3. Computational support was provided by the Regional Computing Centre (RRZK) of the University of Cologne.

Topical Editor D. Murtagh thanks M. Santee and another referee for their help in evaluating this paper.

\section{References}

Abbatt, J. P. D. and Molina, M. J., The heterogeneous reaction of $\mathrm{HOCl}+\mathrm{HCl} \rightarrow \mathrm{Cl}_{2}+\mathrm{H}_{2} \mathrm{O}$ on ice and nitric acid trihydrate: reaction probabilities and stratospheric implications, Geophys. Res. Lett., 19, 461-464, 1992.
Baier, F., Entwicklung und Anwendung eines adjungierten Modells zur Simulation des Ozonhaushaltes der Stratosphäre während realer Episoden, in Mitteilungen aus dem Institut für Geophysik und Meteorologie der Universität zu Köln, (Eds) Kerschgens, M., Neubauer, F. M., Pätzold, M., Speth, P., and Tezkan, B., ISSN 0069-5882, 141, 154, Köln, Germany, 2000.

Baulch, D. L., Duxbury, J., Grant, S. J., and Montague, D. C., Evaluated kinetic Data for high temperature reactions, Vol. 4, Homogeneous Gas Phase Reactions of Halogen and Cyanide Containing Species, J. Phys. Chem. Ref. Data, 10, Suppl. 1, 721, 1981.

Berger, U. and Dameris, M., Cooling of the upper atmosphere due to $\mathrm{CO}_{2}$ increase: a model study, Ann. Geophysicae, 11, 809-819, 1993.

Berger, U. and Ebel, A., Dependence of the energy budget at mesopause heights on variable circulation patterns, Adv. Space. Res., 17, 111-116, 1995.

Berger, U. and von Zahn, U., The two-level structure of the mesopause: A model study, J. Geophys. Res., 104, $22083-$ $22093,1999$.

Biele, J., Neuber, R., Warming, J., Beninga, I., von der Gathen, P., Stebel, K., Schrems, O., and Rosen, J., The evolution of polar stratospheric clouds above Spitzbergen in winter 1996/97, in Polar Stratospheric Ozone 1997, Proceedings of the 4th European Symposium, 22 to 26 September 1997, Schliersee, Bavaria, Germany, (Eds) Harris, N. R. P., Kilbane-Dawe, I., and Amanatidis, G. T., European Communities, Luxembourg, 99-102, 1998.

Bott, A., Monotone flux limitation in the area-preserving flux-form advection algorithm, Mon. Wea. Rev., 120, 2592-2602, 1992.

Brasseur, G., Hitchman, M. H., Walters, S., Dymek, M., Falise, E., and Pirre, M., An interactive chemical dynamical radiative twodimensional model of the middle atmosphere, J. Geophys. Res., 95, 5639-5655, 1990.

Browell, E. V., Buttler, C. F., Ismail, S., Robinette, P. A., Carter, A. F., Higdon, N. S., Toon, O. B., Schoeberl, M. R., and Tuck, A. F., Airborne lidar observations in the wintertime Arctic stratosphere: polar stratospheric clouds, Geophys. Res. Lett., 17, 385388, 1990.

Brühl, C., Carslaw, K., Peter, T., Grooß, J.-U., Russel III, J. M., and Müller, R., Chlorine activation and ozone depletion in the Arctic vortex of the four recent winters using a trajectory box model and HALOE satellite observations, in Proc. XVIII Quadrennial Ozona Symp., L'Aquila, 12-21 September 1996, 675-678, 1997.

Burkholder, J. B., Talukdar, R. K., and Ravishankara, A. R., Temperature dependence of the $\mathrm{ClONO}_{2} \mathrm{UV}$ absorption spectrum. Geophys. Res. Lett., 21, 585-588, 1994.

Carslaw, K. S., Luo, B. P., Clegg, S. L., Peter, T., Brimblecombe, P., and Crutzen, P. J., Stratospheric aerosol growth and $\mathrm{HNO}_{3}$ gas phase depletion from coupled $\mathrm{HNO}_{3}$ and water uptake by liquid particles, Geophys. Res. Lett., 21, 2479-2482, 1994.

Carslaw, K. S., Luo, L., and Peter, T., An analytic expression for the composition of aqueous $\mathrm{HNO}_{3}-\mathrm{H}_{2} \mathrm{SO}_{4}$ stratospheric aerosols including gas phase removal of $\mathrm{HNO}_{3}$, Geophys. Res. Lett., 22, 1877-1880, 1995.

Carslaw, K. S., Peter, T., and Müller, R., Uncertainties in reactive uptake coefficients for solid stratospheric particles-2. Effect on ozone depletion, Geophys. Res. Lett., 24, 1747-1750, 1997.

Carslaw, K. S., Peter, T., Bacmeister, J. T., and Eckermann, S. D., Widespread solid particle formation by mountain waves in the Arctic stratosphere, J. Geophys. Res., 104, 1827-1836, 1999.

Dameris, M., Berger, U., Günther, G., and Ebel, A., The ozone hole: dynamical consequences as simulated with a three-dimensional model of the middle atmosphere, Ann. Geophysicae, 9, 661-668, 
1991.

DeMore, W. B., Sander, S. P., Golden, D. M., Hampson, R. F., Kurylo, M. J., Howard, C. J., Ravishankara, A. R., Kolb, C. E., and Molina, M. J., Chemical kinetics and photochemical data for use in stratospheric modeling, Eval. 11, JPL Publ. 94-26, Natl. Aeronaut. and Space Admin., Jet Propul. Lab., Calif. Inst. of Technol., Pasadena, 1997.

Deshler, T., Johnson, B. J., and Rozier, W. R., Balloon-borne measurements of Pinatubo aerosol during 1991 and 1992 at $42^{\circ} \mathrm{N}$ : Vertical profiles, size distribution, and volatility, Geophys. Res. Lett., 20, 1435-1438, 1993.

Drdla, K., Turco, R. P., and Elliott, S., Heterogeneous chemistry on Antarctic polar stratospheric clouds: a microphysical estimate of the extent of chemical processing, J. Geophys. Res., 98, 89658981, 1993.

Dye J. E., Baumgardner, D., Gandrud, B. W., Kawa, S. R., Kelly, K. K., Loewenstein, M., Ferry, G. V., Chan, K. R., and Gary, B. L., Particle size distributions in Arctic polar stratospheric clouds, growth and freezing of sulfuric acid droplets, and implications for cloud formation, J. Geophys. Res., 97, 8015-8034, 1992.

Froidevaux L., Read, W. G., Lungu, T. A., Cofield, R. E., Fishbein, E. F., Flower, D. A., Jarnot, R. F., Ridenoure, B. P., Shippony, Z., Waters, J. W., Margitan, J. J., McDermid, I. S., Stachnik, R. A., Peckham, G. E., Braathen, G., Deshler, T., Fishman, J., Hofmann, D. J., and Oltmans, S. J., Validation of UARS microwave limb sounder ozone measurements, J. Geophys. Res., 101, 10 017-10060, 1996.

Goodeve, C. F. and Taylor, A. W. C., The continuous absorption spectrum of hydrogen bromide, Proc. Roy. Soc. London, Ser. A, 152, 221-230, 1935.

Granier, C. and Brasseur, G., Impact of heterogeneous chemistry on model predictions of ozone changes, J. Geophys. Res., 97, 18 015-18 033, 1992.

Günther, G., Die numerische Simulation von Transportprozessen in der mittleren Atmosphäre, in Mitteilungen aus dem Institut für Geophysik und Meteorologie der Universität zu Köln, (Eds) Ebel, A., Kerschgens, M., Neubauer, F. M., and Speth, P., ISSN 0069-5882, 104, 114 pp., Köln, Germany, 1995.

Günther, G. and Baier, F., Simulation of the dynamics and chemistry of the polar vortex during winter 1995/96, in Polar Stratospheric Ozone 1997, Proceedings of the 4th European Symposium, 22 to 26 September 1997, Schliersee, Bavaria, Germany, (Eds) Harris, N. R. P., Kilbane-Dawe, I., and Amanatidis, G. T., European Communities, Luxembourg, 281-284, 1998.

Günther, G. and Dameris, M., Air mass exchange across the polar vortex edge during a simulated major stratospheric warming, Ann. Geophysicae, 13, 745-756, 1995.

Haltiner, G. J. and Williams, R. T., Numerical prediction and dynamik meteorology, 476 pp., John Wiley \& Sons, New York, 1980.

Hansen, G. and Chipperfield, M. P., Ozone depletion at the edge of the Arctic polar vortex 1996/1997, J. Geophys. Res., 104, 1837$1845,1999$.

Hanson, D. R. and Mauersberger, K., Laboratory studies of the nitric acid trihydrate: implications for the south polar stratosphere, Geophys. Res. Lett., 15, 855-858, 1988.

Hanson, D. R. and Mauersberger, $\mathrm{K}$., $\mathrm{HCl} / \mathrm{H}_{2} \mathrm{O}$ solid-phase vapor pressures and $\mathrm{HCl}$ solubility in ice, J. Phys. Chem., 94, 47004705, 1990.

Hanson, D. R. and Ravishankara, A. R., The reaction probabilities of $\mathrm{ClONO}_{2}$ and $\mathrm{N}_{2} \mathrm{O}_{5}$ on polar stratospheric cloud materials, J. Geophys. Res., 96, 5081-5090, 1991.
Hanson, D. R. and Ravishankara, A. R., Response to "Comment on pororities of ice films used to simulate stratospheric cloud surfaces", J. Phys. Chem., 97, 2802-2803, 1993 a.

Hanson, D. R. and Ravishankara, A. R., Reaction of $\mathrm{ClONO}_{2}$ with $\mathrm{HCl}$ on NAT, NAD, and frozen sulfuric acid and hydrolysis of $\mathrm{N}_{2} \mathrm{O}_{5}$ and $\mathrm{ClONO}_{2}$ on frozen sulfuric acid, J. Geophys. Res., 98, 22 931-22 936, 1993b.

Hendricks, J., Lippert, E., Petry, H., and Ebel, A., Heterogeneous reactions on and in sulfate aerosols: implications for the chemistry of the midlatitude tropopause region, J. Geophys. Res., 104, 5531-5550, 1999.

Hofmann, D. J., Increase in the stratospheric background sulfuric acid aerosol mass in the past 10 years, Science, 248, 996-1000, 1990.

Holloway, J. L., Spelman, M. J., and Manabe, S., Latitude-longitude grid suitable for numerical time integration of a global atmospheric model, Month. Wea. Rev., 101, 69-78, 1973.

Jakobs, H. J., Bischof, M., Ebel, A., and Speth, P., Simulation of gravity wave effects under solstice conditions using a 3-D circulation model of the middle atmosphere, J. Atmos. Terr. Phys., 48, 1203-1223, 1986.

Koop, T., Biermann, U. M., Raber, W., Luo, B. P., Crutzen, P. J., and Peter, T., Do stratospheric aerosol droplets freeze above the ice frost point?, Geophys. Res. Lett., 22, 917-920, 1995.

Koop, T., Carslaw, K. S., and Peter, T., Thermodynamic stability and phase transitions of PSC particles, Geophys. Res. Lett., 24, 2199-2202, 1997a.

Koop, T., Luo, B. P., Biermann, U. M., Crutzen, P. J., and Peter, T., Freezing of $\mathrm{HNO}_{3} / \mathrm{H}_{2} \mathrm{SO}_{4} / \mathrm{H}_{2} \mathrm{O}$ solutions at stratospheric temperatures: nucleation statistics and experiments, J. Phys. Chem., 101, 1117-1133, 1997b.

Knudsen, B. M., Rosen, J. M., Kjome, N. T., and Whitten, A. T., Comparison of analyzed stratospheric temperatures and calculated trajectories with long-duration balloon data, J. Geophys. Res., 101, 19 137-19 145, 1996.

Krüger, B. C. and Fabian, P., Model calculations about the reduction of atmospheric ozone by different halogenated hydrocarbons, Ber. Bunsenges. Phys. Chem., 90, 1062-1066, 1986.

Leu, M.-T., Laboratory studies of sticking coefficients and heterogeneous reactions important in the Antarctic stratosphere, Geophys. Res. Lett., 15, 17-20, 1988.

Luo, B. P., Carslaw, K. S., Peter, T., and Clegg, S. L., Vapor pressures of $\mathrm{H}_{2} \mathrm{SO}_{4} / \mathrm{HNO}_{3} / \mathrm{HCl} / \mathrm{HBr} / \mathrm{H}_{2} \mathrm{O}$ solutions to low stratospheric temperatures, Geophys. Res. Lett., 22, 247-250, 1995.

Manney, G. L., Santee, M. L., Froidevaux, L., Waters, J. W., and Zurek, R. W., Polar vortex conditions during the 1995-96 Arctic winter: Meteorology and MLS ozone, Geophys. Res. Lett., 23, 3203-3206, 1996a.

Manney, G. L., Swinbank, R., Massie, S. T., Gelman, M. E., Miller, A. J., Nagatani, R., O'Neill, A., and Zurek, R. W., Comparison of U.K. Meteorological Office and U.S. National Meteorological Center stratospheric analyses during northern and southern winter, J. Geophys. Res., 101, 10311-10334, 1996 b.

Massie, S. T., Tie, X. X., Brasseur, G. P., Bevilacqua, R. M., Fromm, M. D., and Santee,M. L., Chlorine activation during the early 1995-1996 Arctic winter, J. Geophys. Res., 105, 71117131, 2000.

Orlando, J. J. and Burkholder, J. B., Gas-phase UV/visible absorption spectra of $\mathrm{HOBr}$ and $\mathrm{Br}_{2} \mathrm{O}$, J. Phys. Chem., 99, 1143-1150, 1995.

Poole, L. R. and McCormick, M. P., Airborne lidar observation of Arctic polar stratospheric clouds: indication of two distinct 
growth modes, Geophys. Res. Lett., 15, 21-25, 1988.

Rattigan, O., Lutman, E. R., Jones, R. L., and Cox, R. A., Temperature dependent absorption cross-section and atmospheric photolysis rates of nitric acic. Ber. Bunsenges. Phys. Chem., 96, 399404, 1992.

Ravishankara, A. R. and Hanson, D. R., Differences in the reactivity of type I polar stratospheric clouds depending on their phase, J. Geophys. Res., 101, 3885-3890, 1996.

Rose, K., On the influence of nonlinear wave-wave interaction in a 3-D primitive equation model for sudden stratospheric warmings, Beitr. Phys. Atmosph., 56, 14-41, 1983.

Ruhnke, R., Kouker, W., and Reddmann, T., The influence of the $\mathrm{OH}+\mathrm{NO}_{2}+\mathrm{M}$ reaction on the $\mathrm{NO}_{y}$ partitioning in the late Arctic winter 1992/1993 as studied with KASIMA, J. Geophys. Res., 104, 3755-3772, 1999.

Santee, M. L., Manney, G. L., Read, W. G., Froidevaux, L., and Waters, J. W., Polar vortex conditions during the 1995-96 Arctic winter: MLS $\mathrm{ClO}$ and $\mathrm{HNO}_{3}$, Geophys. Res. Lett., 23, 3207 3210, 1996.

Schoeberl, M. R. and Strobel, D. F., The zonally averaged circulation of the middle atmosphere, J. Atmos. Sci., 35, 577-591, 1978.

Sessler, J., Good, P., MacKenzie, A. R., and Pyle, J. A., What role do type I polar stratospheric cloud and aerosol parameterizations play in modelled lower stratospheric chlorine activation and ozone loss?, J. Geophys. Res., 101, 28 817-28 835, 1996.

Sinnhuber, B.-M., Chipperfield, M. P., Davies, S., Burrows, J. P., Eichmann, K.-U., Weber, M., von der Gathen, P., Guirlet, M., Cahill, G. A., Lee, A. M., and Pyle, J. A., Large loss of total ozone during the Arctic winter of 1999/2000, Geophys. Res. Lett., 27, 3473-3476, 2000.

Steil, B., Dameris, M., Brühl, C., Crutzen, P. J., Grewe, V., Ponater, M., and Sausen, R., Development of a chemistry module for GCMs: first results of a multiannual integration, Ann. Geophysicae, 16, 205-228, 1998.

Tabazadeh, A., Turco, R. P., and Jacobson, M. Z., A model for studying the composition and chemical effects of stratospheric aerosols, J. Geophys. Res., 99, 12 897-12914, 1994.

Thomason, L. W., Poole, L. R., and Deshler, T., A global climatology of stratospheric aerosol surface area density deduced from Stratospheric Aerosol and Gas Experiment II measurements: 1984-1994, J. Geophys. Res., 102, 8967-8976, 1997.

Waters, J. W., Read, W. G., Froidevaux, L., Lungu, T. A., Perun, V. S., Stachnik, R. A., Jarnot, R. F., Cofield, R. E., Fishbein, E. F., Flower, D. A., Burke, J. R., Hardy, J. C., Nakamura, L. L., Ridenoure, B. P., Shippony, Z., Thurstans, R. P., Avallone, L. M., Toohey, D. W., deZafra, R. L., and Shindell, D. T., Validation of UARS Microwave Limb Sounder $\mathrm{ClO}$ measurements, J. Geophys. Res., 101, 10 091-10 127, 1996.

Weisenstein, D. K., Ko, M. K. W., Sze, N. D., and Rodriguez, J. M., Potential impact of $\mathrm{SO}_{2}$ emission from stratospheric aircraft on ozone, Geophys. Res. Lett., 23, 161-164, 1996.

WMO (World Meteorological Organization), Scientific Assessment of Ozone Depletion: 1991. Global Ozone Research and Monitoring Project, Report No. 25, WMO, Geneva, 1992.

WMO (World Meteorological Organization), Scientific Assessment of Ozone Depletion: 1994. Global Ozone Research and Monitoring Project, Report No. 37, WMO, Geneva, 1995.

WMO (World Meteorological Organization), Scientific Assessment of Ozone Depletion: 1998. Global Ozone Research and Monitoring Project, Report No. 44, WMO, Geneva, 1999.

Zhang, R., Wooldridge, P. J., Abbatt, J. P. D., and Molina, M. J., Physical chemistry of the $\mathrm{H}_{2} \mathrm{SO}_{4} / \mathrm{H}_{2} \mathrm{O}$ binary system at low temperatures: Stratospheric implications, J. Phys. Chem., 97, 73517358, 1993.

Zhang, R., Jayne, J. T., and Molina, M. J., Heterogeneous interactions of $\mathrm{ClONO}_{2}$ and $\mathrm{HCl}$ with sulfuric acid tetrahydrate: implications for the stratosphere, J. Phys. Chem., 98, 867-874, 1994.

Zhang, R., Leu, M.-T., and Molina, M. J., Formation of polar stratospheric clouds on preactivated background aerosols, Geophys. Res. Lett., 23, 1669-1672, 1996. 